\title{
JoÃo Henrique de Carvalho
}

\section{Análise da expressão e atividade de}

\author{
receptores ativados por proteases em
}

\section{plaquetas de pacientes com hipertensão}

\author{
arterial pulmonar
}

Dissertação apresentada à Faculdade de Medicina da Universidade de São Paulo para obtenção do título de Mestre em Ciências

Área de concentração: Fisiopatologia Experimental Orientadora: Dra. Nair Yukie Maeda

SÃO PAULO

2009 
Dados Internacionais de Catalogação na Publicação (CIP)

Preparada pela Biblioteca da

Faculdade de Medicina da Universidade de São Paulo

Creprodução autorizada pelo autor

Carvalho, João Henrique de

Análise da expressão e atividade de receptores ativados por proteases em plaquetas de pacientes com hipertensão arterial pulmonar / João Henrique de Carvalho. -- São Paulo, 2009.

Dissertação(mestrado)--Faculdade de Medicina da Universidade de São Paulo para obtenção do título de Mestre em Ciências.

Área de concentração: Fisiopatologia Experimental.

Orientadora: Nair Yukie Maeda.

Descritores: 1.Hipertensão pulmonar 2.Trombose 3.Plaquetas 4.Receptor

PAR-1/agonistas 5.Selectina-P

USP/FM/SBD-027/09 
À Deus,

Por estar sempre ao meu lado dando forças. 
À minha Mãe,

por toda a dedicação, carinho e amor que me transformaram no que sou hoje. 
À minha namorada Ludmilla Lobo de Araújo, por sua paciência e compreensão das minhas ausências, por suas sugestões a respeito da dissertação, e principalmente por todo seu carinho e amor. 


\section{AGRADECIMENTOS}

À minha amiga e orientadora, Dra. Nair Yukie Maeda, por sua dedicação e apoio incansáveis, por ter me ensinado a trabalhar com ética e critérios de seleção rigorosos, por todas as suas críticas e sugestões a respeito de como trabalhar, que hoje, tenho certeza que se incorporaram em mim e me tornaram um profissional mais autônomo e melhor. E claro, por nossa amizade.

À amiga, Dra. Rosangela de Paula Silva Soares, por ter sempre acreditado em mim, por ter "suado a camisa" para me ensinar o máximo possível, sempre com muita calma e paciência, por suas críticas construtivas, e por nossa amizade.

Ao Prof. Dr. Antonio Augusto Barbosa Lopes do Instituto do Coração, pela idealização do projeto, pela análise estatística, mas não só por isso, por ser um verdadeiro didata, por ser um exemplo inspirador de professor e pesquisador.

Ao Prof. Dr. Sergio Paulo Bydlowski da Faculdade de Medicina da USP, por ter me aceito como aluno de iniciação durante a época da faculdade, e por ter me apresentado a Dra. Nair Maeda. Passos iniciais, sem os quais, eu nunca teria chegado à conclusão deste Mestrado.

Ao Prof. Dr. Roger Chammas da Faculdade de Medicina da USP, pelo consentimento incondicional de uso do citômetro de fluxo do LIM24, e também pelas sugestões realizadas próximo a data da qualificação. 
À amiga, Dra. Sonia Maria Ferreira Melo Mesquita do Instituto do Coração, por ter selecionado os pacientes com todo o afinco, viabilizando assim, a realização deste trabalho.

À Dra. Andréia Hanada Otake, por me ensinar muitos fundamentos de citometria de fluxo, por me ajudar na padronização da técnica utilizada neste trabalho, e por nossa amizade.

À Dra. Juliana Pereira, às amigas Graciela, e Carla, do Laboratório de Imunopatologia da Fundação Pró-Sangue Hemocentro de São Paulo, pelo apoio na interpretação dos resultados do citômetro de fluxo, e pelas valiosas sugestões a respeito das análises.

Aos membros da banca de qualificação, Prof. Dr. Antonio Augusto Lopes, Profa. Dra. Guacyara Motta, Profa. Dra. Shigueko Sonohara Troyano Pueyo, pelas sugestões realizadas na qualificação.

À Dra. Maria Aparecida Basile pelo amor à educação, e por todos os ensinamentos passados durante o PAE.

À amiga, Natália Mastantuono Nascimento, por estar sempre de prontidão para as coletas de amostras, pelo apoio na construção e apresentação da aula, mas principalmente por nossa amizade. 
Ao meu grande amigo Fernando Regis de Almeida Camargo, por suas extensas revisões e sugestões sobre a dissertação, e principalmente pela amizade incondicional ao longo do árduo caminhar.

Ao amigo Antonio Carlos Magnanelli por ter me passado um pouco de sua visão crítica da Ciência.

À secretária e amiga Cleide Menarbini Appolonio, pelas ajudas imprescindíveis, por toda sua atenção e amizade.

Às secretárias da Fisiopatologia, Sras. Sonia e Tania, por toda colaboração e carinho.

Aos funcionários da biblioteca, principalmente à Sra. Valéria Vilhena por todo apoio na finalização da dissertação.

Aos amigos do Laboratório de Pesquisa da Fundação Pró-Sangue Hemocentro de São Paulo, Adriana Debis, Adriana Morgan, Andréia, Aruan, Débora, Denise, Ester, Felipe, Fernanda, Fernando, Joel, Jorge, Linah, Luciana, Pâmela, Paula, Pedro, Rafael, Rita, e Samantha.

Aos amigos do Laboratório de Oncologia - LIM24, Gabriela, Guilherme, Gustavo, Lara, Luciana, Patrícia, Rafael, Renata, e Tharcísio.

À todos que de algum modo contribuíram na realização deste trabalho.

Muito obrigado. 
O presente trabalho foi desenvolvido no Laboratório da Superintendência de Pesquisa da Fundação Pró-Sangue Hemocentro de São Paulo e no Laboratório de Oncologia - LIM-24 da Faculdade de Medicina da Universidade de São Paulo, sob o apoio financeiro da Fundação de Amparo à Pesquisa do Estado de São Paulo (FAPESP), processos $\mathrm{n}^{\circ}$ 06/52837-8 e 04/14961-3. 


\section{SUMÁRIO}

\section{LISTA DE ABREVIATURAS}

\section{RESUMO}

\section{SUMMARY}

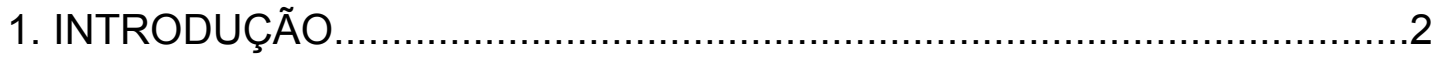

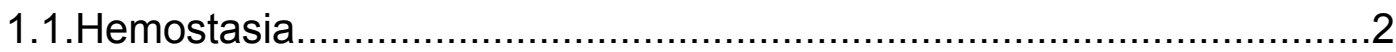

1.2. Receptores ativados por proteases (PARs) ....................................

1.3.Plaquetas e inflamação .............................................................. 10

1.4.Hipertensão arterial pulmonar (HAP) .........................................12

1.4.1. Plaquetas na hipertensão arterial pulmonar ...................... 13

1.4.1.1. Interação entre trombose e inflamação: evidências da ocorrência na HAP...........................................................14

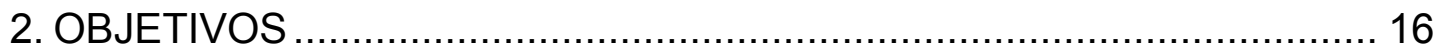

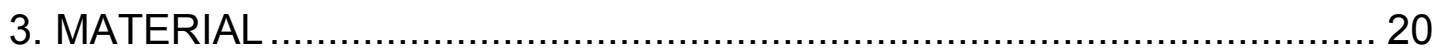

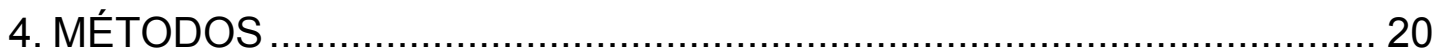

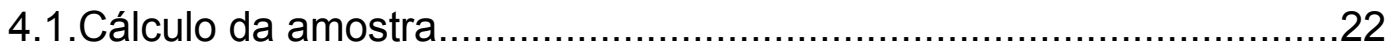

4.2.Critérios de inclusão e exclusão.....................................................22

4.3.Dados diagnósticos e laboratoriais.......................................23

4.4. Coleta de sangue......................................................... 24

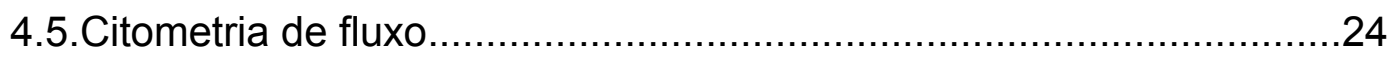

4.5.1. Avaliação da expressão do PAR-1 ...................................... 26

4.5.1.1.Receptores íntegros ....................................... 26

4.5.1.2.Receptores íntegros e clivados ........................... 29 
4.5.2. Avaliação da atividade do PAR-1

4.5.2.1.Atividade do PAR-1 mediante estímulo proteolítico ..... 37

4.5.2.2. Atividade do PAR-1 mediante estímulo não proteolítico.

4.5.3. Avaliação da expressão da selectina-P (CD62P) das plaquetas no estado basal e após estimulação ...............................38

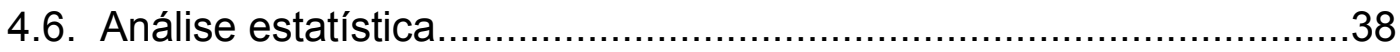

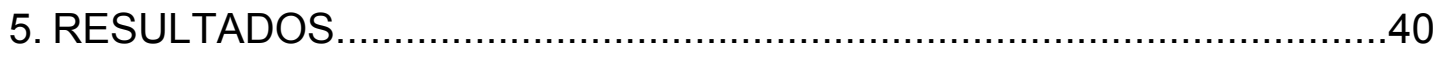

5.1.Pacientes....................................................................... 41

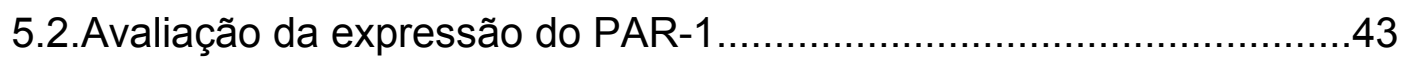

5.2.1. Receptores íntegros (SPAN12) ................................ 43

5.2.2. Receptores íntegros e clivados (ATAP2) ......................... 45

5.3.Avaliação da atividade do PAR-1 .........................................46

5.3.1. Formação de agregados plaqueta-leucócito (APL) ................ 47

5.3.2. Formação de agregados plaqueta-monócito (APM) ............... 48

5.4.Avaliação da expressão da selectina-P (CD62P) das plaquetas no estado basal e após estimulação...................................................50

5.5.Atividade do PAR-1 e eventos correlacionados...........................51

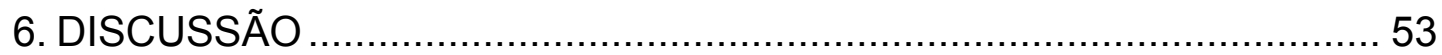

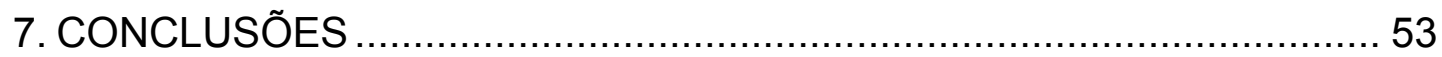

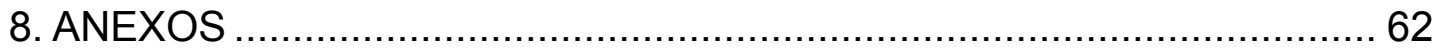

8.1.Avaliação da expressão do PAR-1 ............................................62

8.1.1. Receptores íntegros (SPAN12) ................................. 62

8.1.2. Receptores íntegros e clivados (ATAP2) ..........................6 64

8.2.Avaliação da atividade do PAR-1 ....................................................65 
8.2.1. Formação de agregados plaqueta-leucócito (APL)

8.2.2. Formação de agregados plaqueta-monócito (APM). 66

8.3.Avaliação da expressão da selectina-P das plaquetas no estado basal e após estimulação.

9. REFERÊNCIAS BIBLIOGRÁFICAS 


\title{
LISTA DE ABREVIATURAS
}

\author{
$\mathrm{APL}=$ agregados plaqueta-leucócito \\ APM = agregados plaqueta-monócito \\ $C D$ = grupo de diferenciação \\ $\mathrm{DAG}=$ diacilglicerol \\ $E G F=$ fator de crescimento epidérmico \\ FACS $=$ separador celular ativado por fluorescência \\ FITC = isotiocianato de fluoresceína \\ FSC = dispersão frontal \\ FVW = fator de von Willebrand \\ GP = glicoproteína
}

GPRP = H-Gly-Pro-Arg-Pro-OH (peptídeo inibidor da formação de fibrina)

HAP = hipertensão arterial pulmonar

IFM = intensidade de fluorescência média

IP3 = inositol-trifosfato

PAR-1 = receptor ativado por protease do tipo 1

PAR-2 = receptor ativado por protease do tipo 2

PAR-3 = receptor ativado por protease do tipo 3

PAR-4 = receptor ativado por protease do tipo 4

PDGF $=$ fator de crescimento derivado de plaquetas

$P E=$ ficoeritrina

PerCP = proteína clorofila peridinina

PFA = paraformaldeído

$\mathrm{PKC}=$ proteína quinase $\mathrm{C}$ 
PSGL-1 = glicoproteína ligante do tipo 1 de selectina-P

SFLLRN = H-Ser-Phe-Leu-Leu-Arg-Asn-OH (peptídeo agonista do PAR-1)

SSC $=$ dispersão lateral

TGF $-\beta=$ fator de crescimento transformador do tipo $\beta$

TRAP = peptídeo agonista do receptor de trombina

$\mathrm{TXA}_{2}=$ tromboxano $\mathrm{A}_{2}$

VEGF = fator de crescimento derivado do endotélio vascular

\title{
SINÔNIMOS
}

\author{
$\mathrm{CD} 40 \mathrm{~L}=\mathrm{CD} 154$ \\ CD41/61 $=$ GPIIb/IIla $=$ integrina $\alpha_{\| b} \beta_{3}$ \\ $\mathrm{CD} 42 \mathrm{a}=\mathrm{GPIX}$ \\ $\mathrm{CD} 42 \mathrm{~b}=\mathrm{GPIba}$ \\ CD62 $\mathrm{P}=$ selectina- $\mathrm{P}$
}




\section{RESUMO}

Carvalho, JH. Avaliação da atividade e expressão de receptores ativados por proteases em plaquetas de pacientes com hipertensão arterial pulmonar [Dissertação]. São Paulo: Faculdade de Medicina, Universidade de São Paulo; 2009. 94p.

A hipertensão arterial pulmonar é uma síndrome clínica e hemodinâmica, caracterizada pelo aumento de resistência vascular na microcirculação. A vasoconstrição presente na doença ocorre principalmente devido à disfunção endotelial, induzindo a um estado pró-trombótico onde a participação das plaquetas é inequívoca. A trombina, principal agonista da ativação plaquetária, exerce seus efeitos nas células por meio de receptores ativados por proteases. Através da citometria de fluxo, este trabalho teve por objetivo analisar (1) a expressão do receptor ativado por protease do tipo 1 (PAR-1) na membrana de plaquetas, em seu estado íntegro ou clivado, (2) a atividade, mediante a formação de agregados entre plaquetas e leucócitos e, plaquetas e monócitos após estímulo de receptores ativados por proteases, além (3) da expressão de selectina-P na membrana plaquetária após estimulação. Foram estudados 30 pacientes portadores de hipertensão arterial pulmonar sob tratamento ambulatorial no Instituto do Coração da Faculdade de Medicina da Universidade de São Paulo. A idade destes pacientes variou de 11 a 78 anos, e a média da pressão sistólica da artéria pulmonar foi de $89 \pm 29 \mathrm{mmHg}$. Em $30 \%$ dos pacientes, o número de plaquetas esteve abaixo de $150 \times 10^{3} / \mu \mathrm{l}$, e em $40 \%$, o nível do hematócrito apresentou-se acima de $50 \%$. No presente estudo, não foi observada diferença significante na expressão do PAR-1 íntegro em plaquetas de pacientes comparativamente aos controles $(p=0,2)$. Em contrapartida, as plaquetas dos pacientes apresentaram menor quantidade de receptor clivado $(p=0,01)$, sugerindo internalização destes receptores. Com relação à avaliação da atividade de PAR-1 através da formação de agregados entre 
plaquetas e leucócitos e, plaquetas e monócitos após estimulação por agentes capazes de atuar sobre o receptor de trombina, não foram observadas diferenças entre pacientes e controles, ou seja, em ambos os casos houve a formação de agregados ( $p=0,2$ e $p=0,4$, respectivamente). Em relação aos leucócitos, o SFLLRN, estimulou o receptor independentemente do seu estado, íntegro ou clivado, nos pacientes $(p<0,05)$, enquanto que nos indivíduos normais, a resposta só foi observada quando o receptor íntegro foi estimulado por trombina $(p<0,05)$. Tanto nos pacientes estudados, como nos controles, a estimulação do PAR-1 plaquetário, promoveu aumento da expressão de selectina-P na superfície plaquetária $(p<0,0001)$, embora não houvesse diferença entre os grupos $(p=0,9)$. Estes resultados demonstram que as plaquetas dos pacientes não são refratárias à liberação de seu conteúdo granular, e encontram-se aptas a responder aos estímulos tanto quanto as plaquetas dos controles. Este estudo reforça a importância da terapia antiplaquetária em pacientes com hipertensão arterial pulmonar.

Descritores: 1 - Hipertensão pulmonar, 2 - Trombose, 3 - Plaquetas, 4 -Receptor PAR-1/Antagonistas, 5- Selectina-P. 


\section{SUMMARY}

Carvalho, JH. Platelet protease-activated receptors expression and activity in patients with pulmonary arterial hypertension [Dissertação]. São Paulo: Faculdade de Medicina, Universidade de São Paulo; 2009. 94p.

Pulmonary hypertension is a clinical and hemodynamic syndrome, characterized by the increase of vascular resistance in lungs, generally through various mechanisms, involving vasoconstriction and remodeling of the arterial wall. Endothelial dysfunction in pulmonary arterial hypertension leads to a prothrombotic status, in which platelet participation seems to be unequivocal. Thrombin is the most potent platelet activator and exerts its effects on cells, through protease-activated receptors. Flow cytometry procedure was employed to assess (1) platelet protease-activated receptor 1 (PAR-1) expression, in both uncleaved and cleaved forms, (2) PAR-1 activity, through platelet-leukocyte and platelet-monocyte aggregates formation in response to the thrombin receptor stimulus, and finally (3) platelet P-selectin expression after stimulus. Thirty patients with pulmonary arterial hypertension (age 11 to 78 years) under treatment at the Heart Institute, University of São Paulo were enrolled. The systolic pulmonary arterial pressure was $89 \pm 29 \mathrm{mmHg}$. The platelet count was $<150 \times 10^{3} / \mu \mathrm{l}$ in $30 \%$ of the patients, and the hematocrit level was $>50 \%$ in $40 \%$ of the patients. In the present study, there was no relevant difference in the level of intact platelet proteaseactivated receptor 1 expression in patients and controls $(p=0.2)$. On the other hand, the expression of cleaved receptors was decreased in patients $(p=0.01)$ platelets, what suggests internalization. There was no difference on platelet-leukocyte, and platelet-monocyte aggregates in response to the thrombin receptor stimulus between patients and controls, in other words, in both cases there was the aggregates formation $(p=0.2)$. However, aggregates formation in patients appeared to occur predominately in response to an agent (SFLLRN) capable to stimulate the receptor, 
independent of its state, intact or cleaved $(p<0.05)$. Otherwise, in healthy individuals, the response occurred especially when the intact receptor was stimulated by thrombin $(p<0.05)$. In these patients, similarly to the controls, platelet protease-activated receptor 1 stimulation induced membrane P-selectin expression $(p<0.001)$, although there was no difference between the groups $(p=0.9)$. These findings suggest that platelets from patients are not refractory to its granular content secretion and are capable to respond to stimulus as the controls platelets. This study re-enforce the importance of anti platelet therapy in pulmonary arterial hypertension patients.

Descriptors: 1 - Pulmonary hypertension, 2 -Thrombosis, 3 - Platelets, 4 - Protease activated receptor $1 /$ antagonists, 5 - P-Selectin. 
INTRODUÇÃO 


\section{INTRODUÇÃO}

\subsection{Hemostasia}

A interação existente entre o endotélio, as plaquetas e a cascata da coagulação é a principal responsável pela manutenção da hemostasia sanguínea. (Frenette et al., 1995). As plaquetas são formadas após maturação e fragmentação citoplasmática dos megacariócitos na medula óssea. Entre as células presentes no sangue, as plaquetas são as menores, com tamanho e volume celular normal variando de 2 a $5 \mu \mathrm{m}$ de diâmetro, e de 6 a 10 fentolitros, respectivamente. A vida média das plaquetas é de 7 a 10 dias e após este período sofrem hemocaterese através do sistema reticulo endotelial (Ebbe, 1976).

As plaquetas circulam pelos vasos sanguíneos como células individuais, sem interagir com outras plaquetas, ou outros tipos celulares. A transição para um estado adesivo, pode ser rapidamente iniciado, se essas plaquetas forem expostas a estímulos agonistas (Figura 1). A partir da lesão do endotélio ocorre a vasoconstrição reflexa, potencializada pela ação da endotelina-1 secretada pelas células endoteliais. Com a exposição do tecido subendotelial (altamente trombogênico) rico em fator de von Willebrand (FVW), colágeno e trombospondina, inicia-se o processo de adesão. 


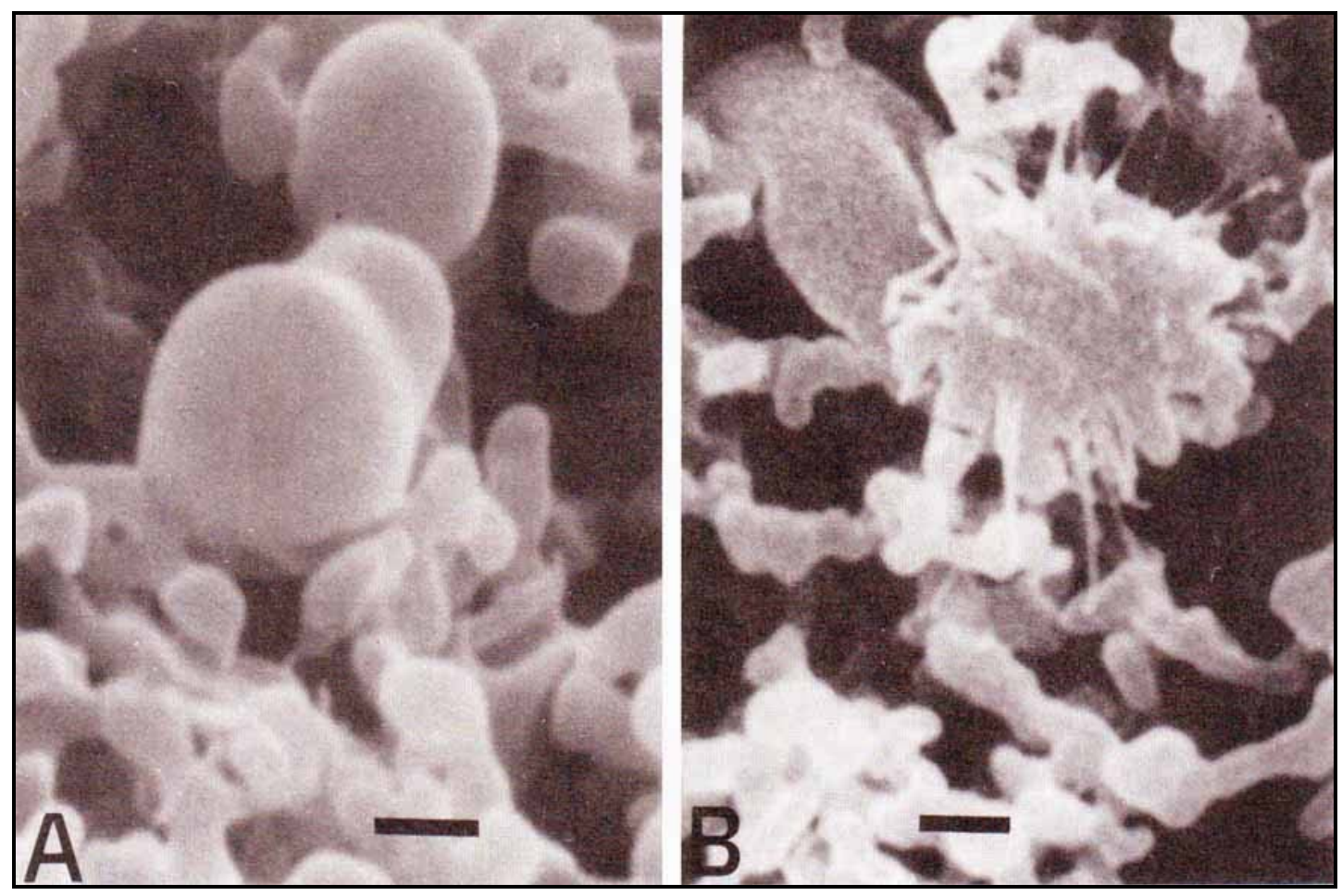

Figura 1 - Elementos celulares circulantes observados através de microscopia eletrônica de varredura. (A) Aspecto rugoso e esférico de plaquetas não ativadas em um filtro de celulose. (B) Morfologia de plaquetas ativadas com perda da rugosidade e liberação de pseudópodes. Exemplo representativo de um paciente com hipertensão arterial pulmonar (Lopes et al., 1993).

Dois dos principais receptores de adesão da plaqueta são a (glicoproteina) GPVI, que possui sítio de ligação para colágeno, e o complexo glicoproteico Ib-IX-V, que possui sítio de ligação para o FVW. Durante a adesão, as plaquetas sofrem a ação de agonistas presentes no microambiente, que podem então estimular a secreção do conteúdo dos grânulos plaquetários. Os constituintes desses grânulos incluem substâncias como o tromboxano $\mathrm{A}_{2}\left(\mathrm{TXA}_{2}\right)$ e o $\mathrm{ADP}$, que ativam plaquetas circulantes levando-as a adquirir propriedades adesivas, o fator de crescimento transformador do tipo $\beta$ (TGF- $\beta$ ), o qual é capaz de induzir a expressão de endotelina-1 pelas células endoteliais, o fator de crescimento derivado das 
plaquetas (PDGF), o fator de crescimento do endotélio vascular (VEGF), o fator de crescimento epidérmico (EGF), (Markewitz et al., 2001; Ruggeri, 2002; Shi e Massague, 2003; Wagner e Burger, 2003), e a serotonina, que além de ser moduladora do tônus vascular é também um fator de crescimento para células musculares lisas (Konishi et al., 2002; Andre, 2004). Após adesão, as plaquetas sofrem mudança de forma, o que permite a formação de múltiplas e firmes conexões entre a superfície da plaqueta e a matriz subendotelial. Essas múltiplas conexões são essenciais para a associação e estabilização entre as plaquetas e a matriz subendotelial sob fluxo sanguíneo (Brass, 2005). As plaquetas estimuladas interagem umas com as outras, principalmente através de pontes formadas pela integrina $\alpha_{\| b} \beta_{3}$ e o fibrinogênio durante a agregação, permitindo assim a formação de um tampão efetivo que previne a perda de sangue. Esta série de respostas plaquetárias que incluem ativação, adesão, liberação de pseudópodes, secreção e finalmente a agregação, é essencial para a hemostasia (Plow e Abrams, 2005). No entanto, essas respostas plaquetárias, quando ocorrem devido à disfunção endotelial, ou devido ao rompimento de uma placa aterosclerótica, resultam na formação de trombo plaquetário, o qual dependendo da extensão compromete a integridade do vaso sanguíneo, levando a trombose. No outro extremo, anormalidades hereditárias (ex. trombastenia de Glanzmann, síndrome de Bernard-Soulier), ou adquiridas (ex. trombocitopenia induzida por drogas) das propriedades adesivas das plaquetas, podem causar hemorragias (Andrews et al., 2004). Sendo assim, 
o equilíbrio da capacidade adesiva e secretora das plaquetas é importantíssimo para a hemostasia.

\subsection{Receptores ativados por proteases (PARs)}

A trombina é uma serinoprotease plasmática, formada nos sítios de injúria vascular após a clivagem do seu precursor (protrombina) pelo complexo ativado de fatores da coagulação VII/X. Além de converter o fibrinogênio em fibrina, e exercer diversos efeitos celulares, incluindo a estimulação do crescimento celular, a produção de inositol-trifosfato, a supressão da concentração de AMPc, e a associação do fosfatidilinositol-3 quinase com tirosina quinase do tipo não receptor (Hirano e Kanaide, 2003), a trombina ativa plaquetas fazendo com que estas exponham na membrana plasmática a selectina-P e o CD154 (CD40L), além de ativar a integrina $\alpha_{l 1 b} \beta_{3}$ (Stenberg et al., 1985; Henn et al., 1998). Além das plaquetas, a trombina também é capaz de ativar células endoteliais, leucócitos e células mesenquimais através da clivagem de receptores de membrana específicos, conhecidos como receptores ativados por proteases (PARs).

Em 1991, o primeiro receptor ativado por proteases foi clonado, seqüenciado, e identificado como receptor ativado por protease do tipo 1 (PAR-1). Este receptor tem massa molecular de aproximadamente $66 \mathrm{kDa}$, é formado por uma cadeia polipeptídica simples, e faz parte da família dos receptores de membrana acoplados à proteína G com sete domínios transmembrana (Vu et al., 1991). Os PARs agem como delicados sensores na presença de proteases extracelulares, e auxiliam a célula a responder à 
nova conformação que é resultado de proteólise (Coughlin, 2000; Hollenberg e Compton, 2002). Os quatro primeiros membros identificados como PARs foram o PAR-1, o PAR-2, o PAR-3 e o PAR-4. O PAR-1 está presente nas plaquetas humanas e tem grande importância na sua ativação, pois pode ser ativado mesmo por concentrações de trombina abaixo do fisiológico (1 nM) (Day et al., 2006; Kahn et al., 1998). O PAR-2 funciona como um receptor para a protease tripsina, mas não para trombina (Nystedt et al., 1994). O PAR-3 está presente nas plaquetas de camundongos atuando como um co-fator da ativação do PAR-4 em baixas concentrações de trombina (Ishihara et al., 1997). A ativação de plaquetas humanas através do PAR-4 está envolvida com o início da geração de trombina e no desenvolvimento da elasticidade do coágulo. Existem pelo menos três receptores para trombina nas plaquetas humanas, o PAR-1, o PAR-4 e o complexo GPlb-IX-V (Vretenbrant et al., 2007).

As proteases não se ligam simplesmente ao seu receptor e o ativam, elas promovem a clivagem, para que o próprio receptor se auto-ative. 0 mecanismo de ativação dos PARs ocorre quando agonistas (serinoproteases) clivam o N-terminal extracelular em local específico e produzem um novo $\mathrm{N}$-terminal que age como ligante para o receptor, inicia a sinalização intracelular, e promove a reposta celular (Dery et al., 1998; MacFarlane et al., 2001). A fração N-terminal do PAR-1 é formada pelos aminoácidos $\quad . .{ }_{35} \mathrm{NATLDPR}_{41} \leftrightarrow{ }_{42}$ SFLLRNPNDKYEPFWEDEEKNES ${ }_{64 . .}$, onde “R $\mathrm{R}_{41} \leftrightarrow{ }_{42} \mathrm{~S}$ ", indica o sítio onde a trombina cliva esse receptor (Figura 2). Esta clivagem gera o novo N-terminal $\left({ }_{42} \mathrm{SFLLRN}_{47} \ldots\right)$ que auto-ativa o receptor 
(Vu et al., 1991). "In vitro", o PAR-1 pode ser ativado sem a proteólise, pelo uso de um peptídeo agonista sintético específico, o SFLLRN. Este hexapeptídeo (H-Ser ${ }^{42}$-Phe-Leu-Leu-Arg-Asn $\left.{ }^{47}-\mathrm{OH}\right)$ corresponde aos resíduos do receptor de trombina e causa degranulação e agregação das plaquetas (Hung et al., 1992; Vassallo et al., 1992).

O PAR-1 pode ser identificado na membrana plaquetária tanto em sua forma não ativada (íntegra) como na forma ativada (após clivagem pela trombina). Para tanto, quando são realizados testes "in vitro", todo o procedimento deve ser realizado a $4^{\circ} \mathrm{C}$ para evitar que após a clivagem, o receptor possa ser internalizado.

O anticorpo anti-PAR-1 correspondente ao clone ATAP2, reconhece os aminoácidos SFLLRNPNDKYEPF, que estão após o sítio de clivagem da trombina (Figura 2), portanto identifica tanto receptores íntegros, quanto os clivados. A forma íntegra do receptor pode ser identificada através do anticorpo correspondente ao clone SPAN12, que reconhece os aminoácidos NATLDPR/SFLLR, envolvidos no sítio de clivagem da trombina (Brass et al., 1994). 


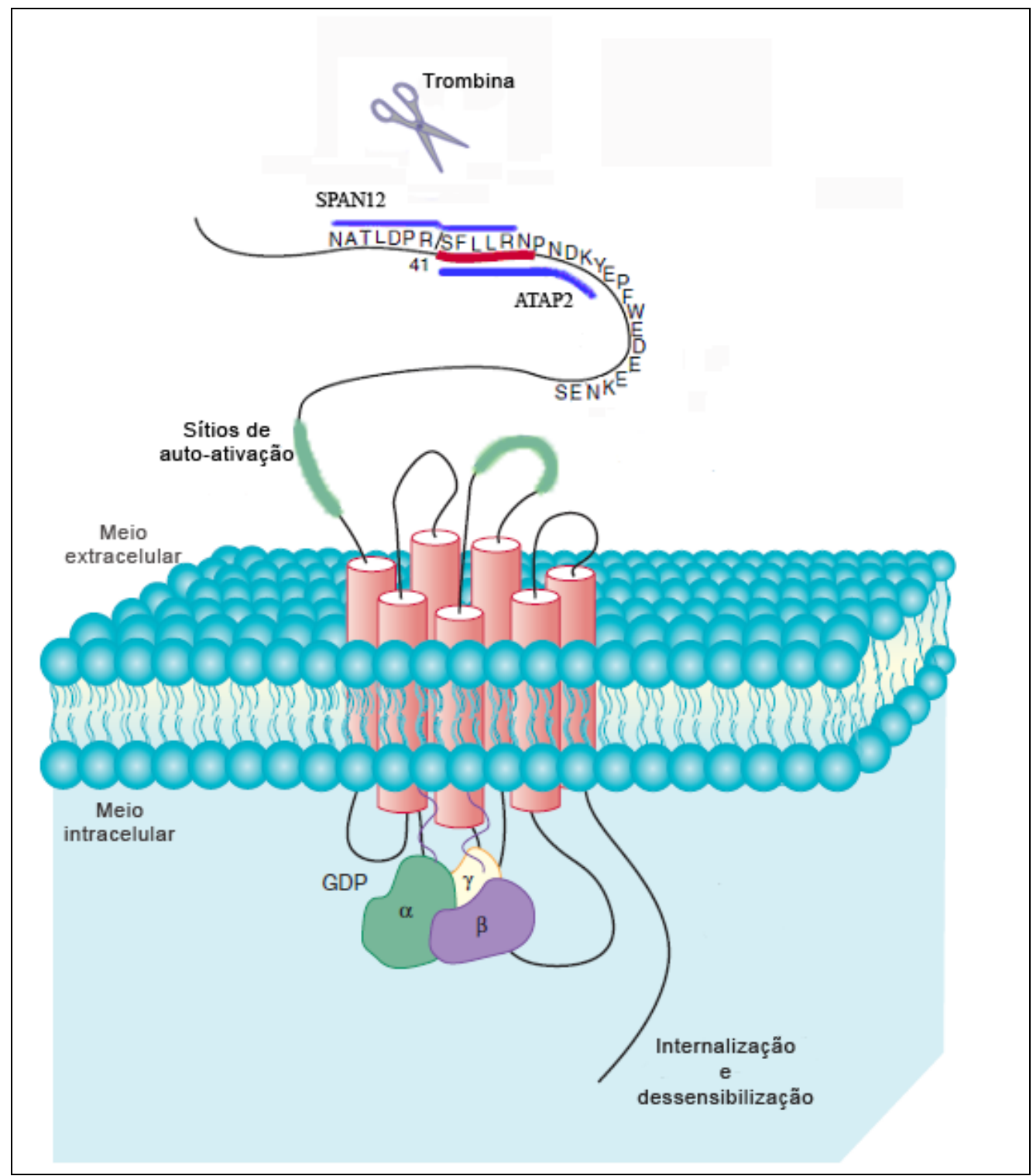

Figura 2 - Estrutura e características do PAR-1 plaquetário humano. Nesta figura podem ser observadas a fração $\mathrm{N}$-terminal extracelular, a região sete domínios transmembrana, e a proteína $\mathrm{G}$ com suas porções $\alpha, \beta$ e $\gamma$. No $\mathrm{N}$ terminal há uma seqüência de aminoácidos entre os resíduos 35 e 64 . Estão demonstrados o sítio de clivagem da trombina entre os aminoácidos $\operatorname{Arg}^{41} \mathrm{e}$ $\mathrm{Ser}^{42}$; o peptídeo auto-ativador do receptor SFLLRN (sublinhado em vermelho); e as seqüências peptídicas utilizadas para a preparação dos anticorpos SPAN12 e ATAP2 (sublinhadas em azul), (adaptado de Brass et al., 1994; Brass, 2005).

A partir da auto-ativação do receptor, ocorre uma alteração conformacional na região C-terminal intracelular que permite o acoplamento da proteína $G$, com conseqüente liberação das subunidades $\beta$ e $\gamma$. $A$ 
proteína G se torna ativada com a liberação da GDP (guanosina difosfato), e a ligação da GTP (guanosina trifosfato). Uma vez ativada, a proteína $\mathrm{G}$ ativa então a fosfolipase $C \beta$ (PLC $\beta$ ), a qual hidrolisa o fosfatidilinositol-bifosfato (PIP2) em dois importantes compostos, o diacilglicerol (DAG) e o inositol-trifosfato (IP3). O IP3 se liga aos canais de $\mathrm{Ca}^{2+}$ do sistema tubular denso, liberando o $\mathrm{Ca}^{2+}$ para o citosol. O DAG e o $\mathrm{Ca}^{2+}$ ativam a proteína quinase $C(P K C)$ na membrana plasmática da plaqueta. $O$ aumento dos níveis de $\mathrm{Ca}^{2+}$ juntamente com a PKC são eventos cruciais no desencadeamento de respostas plaquetárias como o rearranjo do citoesqueleto, a liberação do conteúdo dos grânulos, a mobilização de ácido araquidônico, o rearranjo dos fosfolípides na membrana, e a ativação da integrina $\alpha_{\mathrm{Ilb}} \beta_{3}$ (Offermanns, 2006).

A clivagem do PAR-1 pela trombina é um evento importante, que rapidamente aciona a agregação plaquetária e pode causar trombose arterial, mesmo sob rápido fluxo sanguíneo (Andrade-Gordon et al., 2001; Bahou, 2002).

A presença do PAR1 nas plaquetas dos pacientes com hipertensão arterial pulmonar avaliada através do anticorpo SPAN12 ou do anticorpo ATAP2, seria uma evidência adicional de que as plaquetas podem responder normalmente a serinoproteases endógenas, como por exemplo, a trombina (Ramström et al., 2007). 


\subsection{Plaquetas e inflamação}

Como já descrito anteriormente, durante o processo de adesão, as plaquetas tornam-se ativadas e liberam um arsenal de potentes substâncias inflamatórias e mitogênicas no microambiente. Desta forma, alteram as propriedades quimiotáticas, adesivas e proteolíticas das células endoteliais. Estas alterações do fenótipo endotelial induzidas por plaquetas dão apoio à quimiotaxia, adesão, e transmigração de monócitos para o sítio da inflamação (Wagner e Burger, 2003).

As plaquetas secretam ou expõem o conteúdo dos grânulos densos, dos grânulos-a, dos lisossomos, do sistema canalicular, ou do citosol e, entre as substâncias secretadas estão proteínas adesivas (fibrinogênio, fibronectina, FVW, trombospondina, vitronectina, selectina-P), fatores de crescimento (PDGF, TGF- $\beta$, EGF, bFGF), quimiocinas (RANTES, fator-4 plaquetário [CXC quimiocina ligante 4], proteína de células endoteliais ativadora de neutrófilos [CXC quimiocina ligante 5]), fatores tipo citocinas (IL-1 $\beta$ [interleucina do tipo-1 beta], CD40 ligante, $\beta$-tromboglobulina), e fatores da coagulação (fator $\mathrm{V}$, fator $\mathrm{XI}$, PAl-1 [inibidor do ativador do plasminogênio do tipo-1], plasminogênio, proteína S). Essas substâncias agem de maneira coordenada e regulam funções biológicas importantes como o processo inflamatório e o recrutamento celular (Gawaz, 2004).

Uma vez ativadas na circulação, as plaquetas se ligam a leucócitos, predominantemente monócitos, formando agregados (Jungi et al., 1986; Rinder et al., 1991). Este processo é iniciado através da ligação da selectina-P na superfície de plaquetas ativadas ao seu receptor nos 
leucócitos, o PSGL-1 (glicoproteína ligante do tipo 1 de selectina-P), (Palabrica et al., 1992; Sarma et al., 2002). A ligação entre plaquetas e leucócitos é então estabilizada por uma série de mecanismos, incluindo a ligação da Mac-1 (CD11b/CD18) leucocitária, e da glicoproteina Iba (CD42b) plaquetária (Simon et al., 2000).

A análise por citometria de fluxo da expressão plaquetária de selectina-P (CD62-P) de superfície, foi previamente considerada ser o "padrão ouro" como marcador da ativação plaquetária. A adesão de plaquetas aos neutrófilos e monócitos é mediada por selectina-P e esta interação heterotípica também pode afetar a sobrevida das plaquetas (Rendu e Brohard-Bohn, 2001). Além disso, plaquetas ativadas "in vivo" rapidamente liberam a selectina-P da superfície para a circulação em forma solúvel (sCD62-P), que continua na circulação funcionalmente ativa (Michelson et al., 1996). Também, foi demonstrado que agregados entre plaquetas e leucócitos são detectáveis no sangue periférico e são marcadores de ativação plaquetária mais sensíveis que a expressão de selectina-P (CD62-P) de superfície plaquetária (Michelson et al., 2001).

Segundo Maugeri e colaboradores, após estimulação das plaquetas por trombina ou SFLLRN, a formação de agregados entre plaquetas e granulócitos é um fenômeno dependente da selectina-P (Maugeri et al., 2007). 


\subsection{Hipertensão arterial pulmonar (HAP)}

A hipertensão pulmonar constitui uma síndrome de etiologia diversa e caracteriza-se por elevação da pressão média arterial pulmonar (ou pressão sistólica da artéria pulmonar) superiores a $25 \mathrm{mmHg}$ em repouso, ou de 30 a $40 \mathrm{mmHg}$ em exercício, avaliadas durante o cateterismo cardíaco (Barst et al., 2004). A última proposta de classificação da hipertensão pulmonar, após revisão e atualização dos conceitos etiopatogênicos e fisiopatológicos, aconteceu em 2003, na Conferência de Veneza, Itália. A primeira categoria classificada desta doença, foi a hipertensão arterial pulmonar (HAP), subdividida em idiopática, familial e relacionada a doenças do colágeno, "shunts" sistêmico-pulmonares congênitos, hipertensão portal, infecção pelo HIV, drogas e toxinas, com envolvimento capilar e/ou venoso importante; e por último, a hipertensão pulmonar persistente do recém-nascido (Simonneau et al., 2004).

A hipertensão arterial pulmonar (HAP) é um processo vaso-oclusivo de grande extensão, onde ocorre obstrução progressiva das pequenas artérias e arteríolas, o que causa aumento da resistência vascular nos pulmões (Rabinovitch, 2001).

A vasoconstrição (ou mais especificamente a diminuição da capacidade de vasodilatação) presente na HAP ocorre principalmente devido à disfunção endotelial. Esta, por sua vez, é caracterizada pelo aumento de síntese de vasoconstritores como a endotelina-1 e o $\mathrm{TxA}_{2}$, e diminuição de síntese de vasodilatadores como o óxido nítrico e a prostaciclina (Giaid e Saleh, 1995). 


\subsubsection{Plaquetas na hipertensão arterial pulmonar}

Há evidências de que as plaquetas participam direta e/ou indiretamente do processo vaso-oclusivo pulmonar. Estudos clínicos, realizados inclusive em nosso laboratório, sugerem consumo crônico das plaquetas nos pacientes com HAP. Tal sugestão se deve aos achados de redução do número de plaquetas circulantes, níveis elevados de um marcador de ativação plaquetária, a $\beta$-tromboglobulina (Caramurú et al., 2003), que é uma substância liberada no estágio de secreção do conteúdo dos grânulos plaquetários, e fosforilação de vários substratos em tirosina (Maeda et al., 2003; Maeda et al., 2005). Sugere-se que o estado "pré-ativado" favorece a formação de agregados circulantes, agregados esses, formados exclusivamente por plaquetas, ou por plaquetas e leucócitos (Lopes et al., 1993). A participação das plaquetas na HAP não se restringe à finalização do processo vaso-oclusivo pulmonar, mas também na progressão, através da liberação dos diversos mediadores já descritos anteriormente $\left(\mathrm{TXA}_{2}\right.$, serotonina, CD40/CD40L, IL1- $\beta, \mathrm{FVW}$, trombospondina, fibrinogênio). Além disso, o PDGF liberado pelas plaquetas promove migração de células musculares lisas da parede arterial pulmonar para a luz do vaso, e ainda, induz proliferação dessas células, resultando na obstrução de pequenas artérias pulmonares (Perros et al., 2008).

Um dos aspectos relacionados à participação das plaquetas na HAP é a comprovação da existência de uma alteração primária (genética) das plaquetas, que foi demonstrada em um paciente com trombocitopatia congênita ("pool storage disease"), caracterizada por um defeito na 
capacidade de armazenamento de serotonina, aumento dos seus níveis plasmáticos, e conseqüentemente aumento da pressão arterial pulmonar (Hervé et al., 1990). O outro aspecto, é a participação secundária das plaquetas, com possível ativação endógena em resposta à disfunção endotelial, exposição do subendotélio, e alterações hemodinâmicas. Assim como existem estudos (Caramurú et al., 2003; Lopes et al., 1993; Maeda et al., 2003; Maeda et al., 2005) sugerindo que a ativação endógena crônica ocorre na HAP, também existem dados indicando não haver provas deste estado "pré-ativado" (Kéreveur et al., 2000). Em um estudo envolvendo pacientes com HAP, onde foram analisados epítopos de superfície por citometria de fluxo, como a expressão da integrina $\alpha_{\| b} \beta_{3}, C D 36, C D 63$, e selectina-P de superfície, o aumento da serotonina plasmática não foi associado à ativação plaquetária (Kéreveur et al., 2000). Portanto, todo o esforço no sentido de caracterizar (ou não) este estado de "pré-ativação" é importante para o entendimento da doença vascular pulmonar.

\subsubsection{Interação entre trombose e inflamação: evidências da ocorrência na HAP}

Alterações vasculares na HAP podem levar à secreção plaquetária de muitos mediadores pró-coagulantes, vasoativos, mitogênicos, e inflamatórios. Além disto, a atividade pró-coagulante e a função fibrinolítica estão alteradas na HAP, e estas por sua vez, são fatores confirmados por evidências de aumento da interação entre as plaquetas e a parede arterial pulmonar (Hervé et al., 2001). Paralelamente, a vaso-oclusão também 
depende da remodelagem dos vasos pulmonares envolvendo células e matriz extracelular, e é um evento deflagrado por diversos mediadores, inclusive células inflamatórias e citocinas. Entre esses mediadores inflamatórios encontra-se o CD40L, uma molécula envolvida em processos inflamatórios e na formação de trombos (Damås et al., 2004).

Está demonstrado que na HAP, mecanismos ligados à inflamação e trombose estão presentes na fisiopatologia do processo vascular oclusivo. Neste sentido, torna-se relevante estudar os mecanismos moleculares que dessem informações adicionais sobre a participação desses eventos combinados (inflamação e trombose), e ao mesmo tempo trouxessem elementos sobre a condição endógena das plaquetas desses pacientes. 


\section{OBJETIVOS}




\section{OBJETIVOS}

\section{Objetivo geral:}

O presente estudo teve como objetivo analisar, em pacientes com HAP, comparativamente aos indivíduos normais, características relacionadas a um dos receptores de trombina (o PAR-1), no sentido de inferir se na condição "in vivo" este receptor seria capaz de mediar eventos ligados à inflamação e trombose.

\section{Objetivos específicos:}

Os objetivos específicos foram verificar em pacientes com HAP:

1. A expressão de PAR-1 plaquetário "in vitro", da maneira mais próxima possível do estado em que se encontra na circulação, levando em consideração a forma do receptor (íntegra, ou clivada).

2. A atividade do PAR-1 pela formação de agregados entre plaquetas e leucócitos, induzida por estímulos capazes de agir na forma integra ou clivada do receptor. Este procedimento foi planejado com vistas a acrescentar informações sobre o estado desse receptor "in vivo", com base em seu funcionamento "in vitro". 
3. A expressão em superfície plaquetária da molécula de adesão selectina-P (CD62P), e testar se a ativação plaquetária via PAR-1 é capaz de aumentar sua expressão.

4.Possíveis correlações entre a expressão e a atividade do PAR-1.

5.Possíveis influências do número de plaquetas circulantes, e do número de hemácias circulantes (hematócrito) na magnitude da formação de agregados entre plaquetas e leucócitos, mediante estimulação do receptor íntegro ou clivado. 


\section{MATERIAL}

O anticorpo SPAN12 marcado com PE foi adquirido de Immunotech (Marseille, França). O anticorpo ATAP2 foi adquirido de Santa Cruz Biotechnology (Santa Cruz, CA, EUA). Os anticorpos CD45-FITC, CD14-PE, CD42a-PerCP, CD62P-PE, os controles isotipos $\lg _{1}-\mathrm{PE}$, $\lg _{2}-\mathrm{PE}$, $\operatorname{lgG}_{1^{-}}$ FITC, IgG 1 -PerCP, o tampão FACS e o tampão de lise FACS foram adquiridos de Becton-Dickinson (San Jose, CA, EUA). O peptídeo GPRP (H-Gly-Pro-Arg-Pro-OH) e o TRAP (peptídeo agonista do receptor de trombina), foram adquiridos de Calbiochem (La Jolla, CA, EUA). O peptídeo agonista do PAR-1, o SFLLRN (H-Ser-Phe-Leu-Leu-Arg-Asn-OH), o anticorpo de cabra anti-lgG de camundongo conjugado com FITC e o paraformaldeído, foram adquiridos de Sigma, (St. Louis, MI, EUA). A trombina foi adquirida de Biopool (Ventura, CA, EUA). Os demais reagentes utilizados foram de altíssimo grau de pureza. 
MÉTODOS 


\section{MÉTODOS}

\subsection{Cálculo da amostra}

Com base em verificações anteriores em nosso laboratório e, considerando uma diferença a ser demonstrada na maioria dos testes, da ordem de 0,75 desvio-padrão, com nível de significância de 0,05 e poder de 0,8, estimamos que a amostra devesse corresponder a 30 pacientes (número exato, 29 casos). Esta estimativa previu a realização de testes bi-caudais em todos os procedimentos.

\subsection{Critérios de inclusão e exclusão}

No presente estudo, foram incluídos trinta pacientes portadores de hipertensão arterial pulmonar, admitidos no Instituto do Coração, Faculdade de Medicina da Universidade de São Paulo, para diagnóstico e tratamento. Somente duas sub-categorias diagnósticas foram consideradas, a hipertensão arterial pulmonar idiopática, e a hipertensão arterial pulmonar associada a cardiopatias congênitas. Nenhuma outra forma de doença vaso-oclusiva pulmonar foi incluída (associada a doenças do tecido conectivo, doenças pulmonares, esquistossomose, infecção pelo vírus HIV, tromboembolismo crônico, hipertensão portal e doença do coração esquerdo). Para inclusão, foi necessária a constatação de pressão sistólica da artéria pulmonar acima de $40 \mathrm{mmHg}$, em repouso, avaliada durante o ecocardiograma. Somente foram incluídos pacientes estáveis, em 
acompanhamento ambulatorial, não tendo sido admitidos indivíduos sob tratamento hospitalar ou uso de drogas vasoativas endovenosas. O uso de anticoagulante oral (varfarina) foi admitido, uma vez que esta medicação é crucial para alguns pacientes, não sendo possível sua suspensão. Entretanto, quanto às drogas com interferências sobre a função plaquetária, as mesmas não foram administradas no período de 15 dias que antecedeu a coleta de material (sangue venoso periférico). O grupo controle, consistiu de vinte e cinco doadores voluntários do Banco de Sangue da Fundação Pró-Sangue Hemocentro de São Paulo, não fumantes, e que estivessem isentos de qualquer medicação no período de 15 dias que antecedeu a coleta. Os pacientes e os controles somente entraram no estudo mediante consentimento livre e esclarecido, tendo assinado o termo correspondente. O protocolo de estudo foi aprovado pelas Comissões Científica e de Ética da Fundação Pró-Sangue Hemocentro São Paulo (protocolo de pesquisa 09/2004), e pela Comissão de Ética para Análise de Projetos de Pesquisa CAPPesq (protocolo de pesquisa 119/06).

\subsection{Dados diagnósticos e laboratoriais}

Após o diagnóstico através da pressão pulmonar, os pacientes foram caracterizados através da idade, sexo, hematócrito, e contagem de plaquetas. 


\subsection{Coleta de sangue}

A coleta de sangue foi feita da forma mais suave possível, de maneira a minimizar a ativação plaquetária. Para tanto, foi realizada através de punção venosa, com agulha calibre 19, e sem oclusão venosa. O sangue foi colocado em tubos contendo citrato de sódio 3,8\%, na proporção de 1:10 $(\mathrm{v} / \mathrm{v})$. As amostras foram processadas em no máximo 30 minutos após a coleta.

\subsection{Citometria de fluxo}

A citometria de fluxo é uma técnica que avalia as propriedades físicas e químicas de células, partículas biológicas, ou outras não biológicas. Enquanto essas passam em um fluído, enfileiradas, e atravessam um ou mais feixes de laser(s) o sistema avalia o ângulo e a direção da luz dispersada, que são indicadores do tamanho, forma, e estrutura destas partículas. Se estas células ou partículas forem marcadas com um, ou mais fluorocromos (FITC, PE, PerCP), o laser os excita, o que provê informações biológicas adicionais, assim como a atividade metabólica, o conteúdo de DNA, e a presença ou não de marcadores intracelulares e de membrana específicos. Elementos ópticos e elétricos precisos captam os pulsos fluorescentes e a luz dispersada, e os convertem em valores digitais, enviando-os para um computador para análise. O poder único dos citômetros de fluxo, é que podem avaliar quantitativamente múltiplos parâmetros simultaneamente de células individuais, e ainda isolar células de interesse. Adicionalmente, a sensibilidade, e a velocidade alcançada pelos 
instrumentos de alto desempenho, possibilitam a detecção de populações e eventos extremamente raros (freqüência inferior a $10^{-6}$ ), assim como célulastronco, células dendríticas, antígenos específicos de células $\mathrm{T}$, e transfectantes genéticos (Shapiro, 2003). Como resultado, as aplicações utilizando-se citometria de fluxo não param de crescer. Uma importante aplicação é a análise de plaquetas, que podem ser amplamente avaliadas em sangue total. Entre os dados que podem ser obtidos estão a atividade, os agregados plaqueta-plaqueta, os agregados plaqueta-leucócito, as micropartículas derivadas de plaquetas, além do fluxo de cálcio.

Para a realização deste trabalho, o citômetro de fluxo FACSCalibur (Becton Dickinson), pertencente ao Laboratório de Oncologia LIM-24, da Faculdade de Medicina da Universidade de São Paulo, teve sua utilização gentilmente cedida pelo Professor Roger Chammas. Este citômetro é equipado com o laser de íon argônio (488nm) e detectores de dispersão (FSC - "forward scatter") para tamanho e (SSC - "side scatter") relacionado com a estrutura interna das células, além de três detectores de emissão de fluorescência (FL1, FL2 e FL3).

Para a análise da expressão, as medidas utilizadas foram, a intensidade de fluorescência média (IFM) das plaquetas positivas expressa em unidade arbitrária, e a porcentagem de plaquetas positivas em relação ao total de eventos (10.000). Para a análise da atividade foi utilizada a porcentagem de agregados plaqueta-leucócito (APL), ou agregados plaqueta-monócito (APM) em relação ao total de eventos adquiridos (10.000) 
Durante a padronização da metodologia todos os anticorpos foram devidamente titulados, e sendo assim, foram sempre utilizados na concentração mais próxima da saturada. Todos os testes realizados com pacientes foram acompanhados com um controle (doador normal).

\subsubsection{Avaliação da expressão do PAR-1}

\subsubsection{Receptores íntegros}

O PAR-1 plaquetário íntegro foi detectado utilizando-se o anticorpo anti-PAR-1, clone SPAN12. Este anticorpo tem a característica de se ligar ao sítio de clivagem da trombina (NATLDPR/SFLLR). Sendo assim, só identifica receptores íntegros (Brass et al., 1992; Molino et al., 1995; Woolkalis et al., 1995).

Para detecção da expressão através do SPAN12, foram feitas alíquotas de $10 \mu \mathrm{l}$ de sangue total, onde foram adicionados $4 \mu \mathrm{l}$ de SPAN12-PE, ou $\operatorname{lgG}_{1}-\mathrm{PE}$ como controle isotipo. Desta etapa em diante todo o procedimento foi realizado em temperatura de $4^{\circ} \mathrm{C}$, para evitar a internalização dos receptores. As alíquotas foram incubadas por 30 minutos no escuro, e em seguida lavadas com a adição de $2 \mathrm{ml}$ de tampão FACS, e posterior centrifugação por 10 minutos a 1200xg. Após a lavagem, os sobrenadantes foram descartados, os sedimentos ressuspendidos em $200 \mu l$ de solução isotônica para citometria de fluxo (tampão FACS) e fixados com igual volume de PFA gelado (concentração final de 1\%). As amostras foram mantidas no escuro e a $4^{\circ} \mathrm{C}$, até serem processadas no citômetro, no período não superior a 24 horas (Reiter et al., 2003; Day et al., 2004). 
A aquisição para avaliação da expressão foi feita na forma logarítmica tanto para os parâmetros de dispersão, quanto para os parâmetros de fluorescência. Foram adquiridos 10.000 eventos dentro de uma janela de leitura para população de plaquetas. Esta janela foi feita baseando-se na distribuição das plaquetas dentro dos eixos de FSC e SSC. Para a análise foram feitas as marcações M1 e M2, que correspondem respectivamente à distribuição de fluorescência do anticorpo controle isotipo, e do anticorpo SPAN12 dentro de seus histogramas. A expressão do PAR-1 foi dada em unidade arbitrária de intensidade de fluorescência média (IFM), e esta foi obtida após a subtração da IFM de M1 do controle isotipo, da IFM de M2 do anticorpo SPAN12.

A Figura 3 mostra o resultado padronizado de um ensaio para detecção da forma íntegra do PAR-1 (utilizando o anticorpo SPAN12, e seu controle isotipo) em um indivíduo controle, em forma de citogramas e histogramas. 


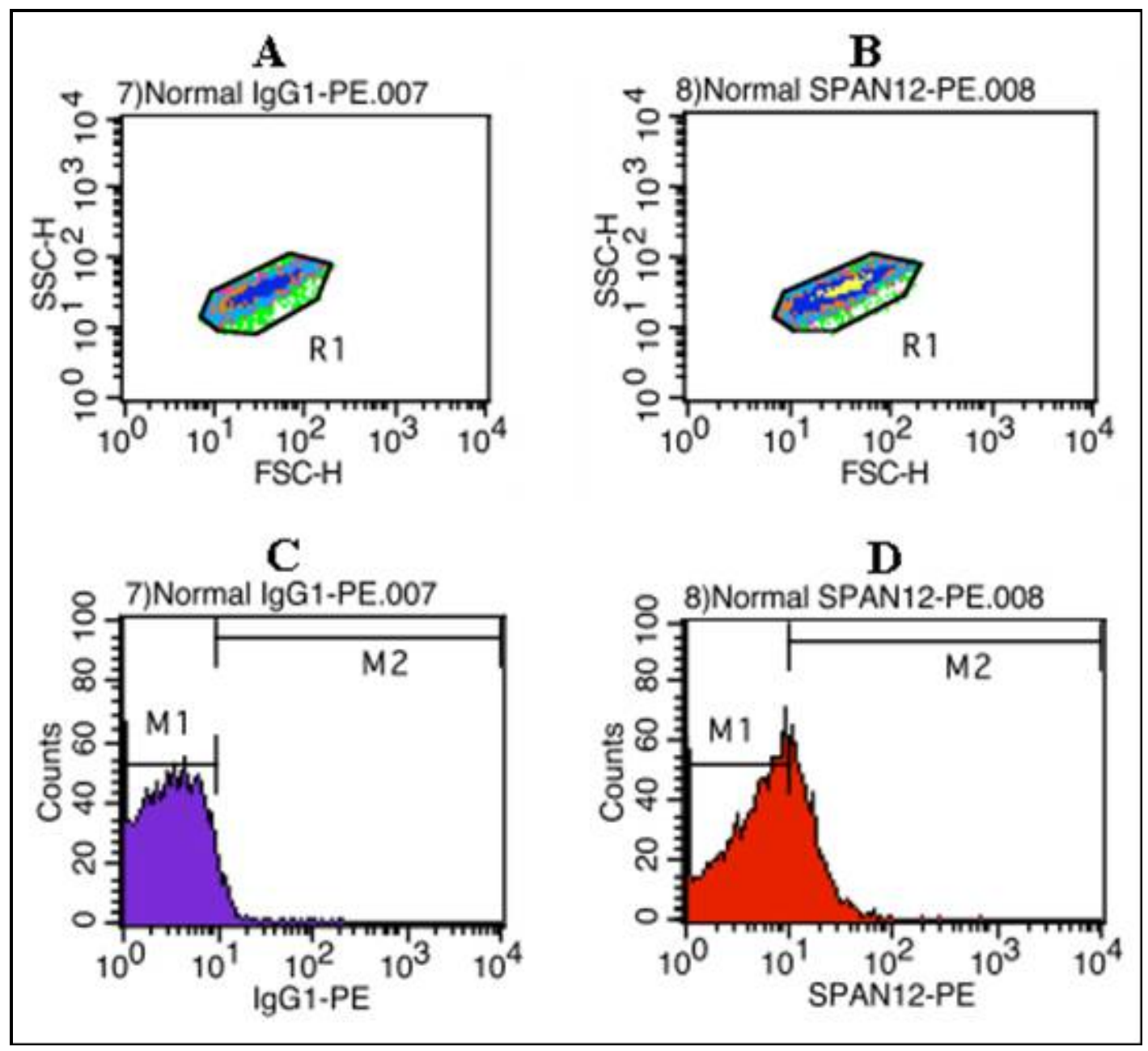

Figura 3 - Os citogramas de densidade, A e B foram obtidos com a utilização do anticorpo isotipo e do anticorpo SPAN12 respectivamente, de um indivíduo controle. Nos citogramas, a dispersão frontal - FSC (parâmetro intimamente ligado ao tamanho dos eventos), está representada na abscissa, e a dispersão lateral - SSC (parâmetro intimamente ligado com a granulosidade dos eventos), está representada na ordenada, ambas em amplificação logarítmica. A população de plaquetas está identificada por uma janela de leitura ("gate") denominada R1, de onde foram adquiridos 10.000 eventos. Os histogramas C e D, respectivamente, correspondem à intensidade de fluorescência de R1 dos citogramas A e B. Nestes, a intensidade dos eventos está representada em amplificação logarítmica na abscissa, e o número relativo de eventos está representado na ordenada. $\mathrm{M} 1$ corresponde à região $\leq 10^{1}$, considerada a região de eventos negativos. M2 corresponde à região $\geq 10^{1}$, local de eventos considerados positivos. 
A Tabela 1, de maneira a complementar os dados da Figura 3, mostra as estatísticas calculadas pelo programa CellQuest, e além disto, explica o cálculo da IFM (intensidade de fluorescência média).

\begin{tabular}{|c|c|c|c|c|}
\hline \multicolumn{5}{|c|}{ Histogram Statistics } \\
\hline \multirow{3}{*}{\multicolumn{3}{|c|}{$\begin{array}{l}\text { File: 7)Normal IgG1-PE.007 } \\
\text { Acquisition Date: } 28 \text {-Feb-08 } \\
\text { Gated Events: } 10000\end{array}$}} & \multicolumn{2}{|c|}{ Log Data Units: Linear Values } \\
\hline & & & \multicolumn{2}{|c|}{ Gate: G1 } \\
\hline & & & \multicolumn{2}{|c|}{ X Parameter: IgG1-PE (Log) } \\
\hline Marker & Left, Right & Events & $\%$ Gated & Mean \\
\hline All & 1,9910 & 10000 & 100.00 & 3.79 \\
\hline M1 & 1,10 & 9605 & 96.05 & 3.33 \\
\hline M2 & 10,9910 & 412 & 4.12 & 14.74 \\
\hline \multicolumn{5}{|c|}{ Histogram Statistics } \\
\hline \multicolumn{3}{|c|}{ File: 8)Normal SPAN12-PE.008 } & \multicolumn{2}{|r|}{ Log Data Units: Linear Values } \\
\hline \multicolumn{3}{|c|}{ Acquisition Date: 28-Feb-08 } & \multicolumn{2}{|r|}{ Gate: G1 } \\
\hline \multicolumn{3}{|c|}{ Gated Events: 10000} & \multicolumn{2}{|r|}{ X Parameter: SPAN12-PE (Log) } \\
\hline Marker & Left, Right & Events & $\%$ Gated & Mean \\
\hline All & 1,9910 & 10000 & 100.00 & 8.31 \\
\hline M1 & 1,10 & 6835 & 68.35 & 4.90 \\
\hline M2 & 10,9910 & 3211 & 32.11 & 15.60 \\
\hline
\end{tabular}

Tabela 1 - Dados estatísticos referentes aos histogramas C e D da Figura 3, fornecidos pelo programa CellQuest. O cálculo da IFM foi realizado com a utilização destes valores. Para tanto, a IFM de M1 (vermelho) do controle isotipo foi subtraída da IFM de M2 (azul) do SPAN12. Exemplo: $M 2-M 1=15,60-3,33=12,27$. Sendo assim, o valor de IFM do SPAN12 deste ensaio é igual a 12,27. O valor da IFM está expresso em unidade arbitrária. As plaquetas positivas para o anticorpo SPAN12 corresponde à porcentagem de eventos presentes em M2 (verde).

\subsubsection{Receptores íntegros e clivados}

Para a detecção do PAR-1 plaquetário independente de clivagem foi utilizado o anticorpo ATAP2. Este anticorpo tem a característica de se ligar 
após o sítio de clivagem da trombina. Sendo assim, identifica tanto os receptores íntegros, quanto os receptores clivados (Brass et al., 1992; Molino et al., 1995; Woolkalis et al., 1995).

A detecção da expressão de PAR-1 através do ATAP2, foi feita utilizando-se alíquotas de $10 \mu \mathrm{l}$ de sangue total, onde foram adicionados $4 \mu \mathrm{l}$ de ATAP2, ou controle isotipo $\operatorname{lgG}_{1}-\mathrm{FITC}$, seguido de incubação por 30 minutos a $4^{\circ} \mathrm{C}$ no escuro. Em seguida, as amostras foram lavadas como descrito anteriormente. Após a lavagem o sobrenadante foi descartado, e o sedimento foi ressuspendido com $50 \mu$ l de tampão FACS. Foi adicionado $1 \mu \mathrm{l}$ de anticorpo de cabra anti-lgG 1 de camundongo conjugado com FITC, seguido de incubação por 60 minutos a $4^{\circ} \mathrm{C}$ no escuro. Após a incubação, as amostras foram lavadas novamente, e os sedimentos foram ressuspendidos com $200 \mu$ l de tampão FACS e fixados com igual volume de PFA gelado (concentração final de $1 \%$ ). As amostras foram mantidas no escuro e a $4^{\circ} \mathrm{C}$, seguido de aquisição no citômetro em até 24 horas (Reiter et al., 2003; Day et al., 2004). A aquisição foi processada como descrito em 4.5.1.1.

A Figura 4 mostra o resultado padronizado de um ensaio de detecção da forma independente de clivagem do PAR-1 (anticorpo ATAP2, e seu controle isotipo) de plaquetas normais de um indivíduo controle. 


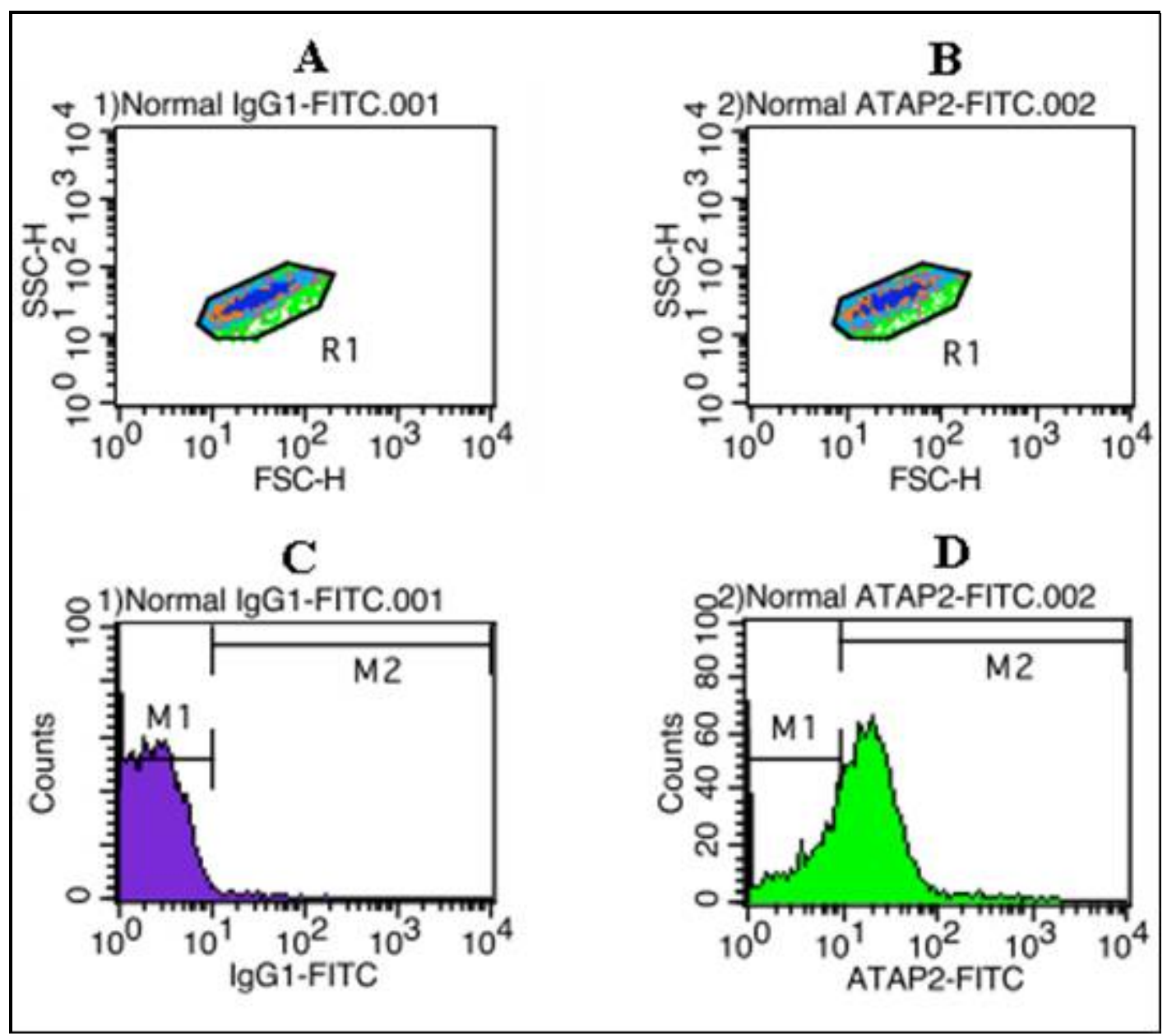

Figura 4 - Os citogramas de densidade, A e B foram obtidos com a utilização do anticorpo isotipo e do anticorpo ATAP2 respectivamente, de um indivíduo controle. Nos citogramas, o tamanho dos eventos está representado na abscissa, e a granulosidade dos eventos está representada na ordenada, ambos em amplificação logarítmica. A população de plaquetas está identificada por uma janela de leitura ("gate") denominada R1, de onde foram obtidos 10.000 eventos. Os histogramas C e $\mathbf{D}$ respectivamente correspondem à intensidade de fluorescência de R1 dos citogramas A e B. Nestes, a intensidade dos eventos está representada em amplificação logarítmica na abscissa, e o número relativo de eventos está representado na ordenada. M1 corresponde à região $\leq 10^{1}$, considerada a região de eventos negativos. M2 corresponde à região $\geq 10^{\top}$, local de eventos considerados positivos. 
A Tabela 2, de maneira a complementar os dados da Figura 4, mostra as estatísticas apresentadas pelo programa CellQuest e, além disto, demonstra que o cálculo da IFM do ATAP2, é realizado de forma idêntica ao SPAN12.

\section{Histogram Statistics}

File: 1)Normal IgG1-FITC.001

Log Data Units: Linear Values

Acquisition Date: 28-Feb-08 Gate: G1

Gated Events: 10000

Total Events: 94573

X Parameter: IgG1-FITC (Log)

\begin{tabular}{rrrrrr} 
Marker & Left, Right & Events & $\%$ Gated & Mean \\
\hline All & 1,9910 & 10000 & 100.00 & 2.58 \\
\hline M1 & 1,10 & 9946 & 99.46 & 2.46 \\
\hline M2 & 10,9910 & 55 & 0.55 & 24.54
\end{tabular}

Histogram Statistics

File: 2)Normal ATAP2-FITC.002

Acquisition Date: 28 -Feb-08

Gated Events: 10000

X Parameter: ATAP2-FITC (Log)

\begin{tabular}{rrrrrr} 
Marker & Left, Right & Events & $\%$ Gated & Mean \\
\hline All & 1,9910 & 10000 & 100.00 & 21.87 \\
M1 & 1,10 & 2730 & 27.30 & 5.48 \\
\hline M2 & 10,9910 & 7305 & 73.05 & 27.93 \\
\hline
\end{tabular}

Tabela 2 - Dados estatísticos fornecidos pelo programa CellQuest referentes aos histogramas $\mathbf{C}$ e D da Figura 4 . O cálculo da IFM foi realizado com a utilização destes valores. Para tanto, a IFM de M1 (vermelho) do controle isotipo foi subtraída da IFM de M2 (azul) do ATAP2. Exemplo: $M 2-M 1=27,93-2,46=25,47$. Sendo assim, o valor de IFM do ATAP2 deste ensaio é igual a 25,47. As plaquetas positivas para o anticorpo ATAP2 correspondem à porcentagem de eventos presentes em M2 (verde). 


\subsubsection{Avaliação da atividade do PAR-1}

A atividade funcional do PAR-1 pode ser estudada "in vitro" mediante estímulos proteolíticos (induzidos por trombina) ou não proteolíticos (induzidos pelo peptídeo agonista do PAR-1, SFLLRN), (Poullis et al., 2000). No entanto, para a utilização de trombina em alíquotas de sangue total, é necessário o uso do peptídeo sintético GPRP, que impede a formação de fibrina, inibindo assim a formação de coágulo, e viabiliza o estudo da atividade através de citometria de fluxo. Em qualquer dos estímulos supracitados, o PAR-1 ativo irá desencadear uma série de mecanismos de sinalização intracelular, que culminará com a expressão de moléculas de adesão na superfície das plaquetas. Entre estas moléculas está a selectina-P, que tem importante papel para formação de agregados entre plaquetas e leucócitos, via receptor leucocitário PSGL-1 (Sako et al., 1993).

O resultado final do estímulo do PAR-1 será a formação de agregados envolvendo plaquetas e leucócitos. Portanto, a medida final de atividade funcional do receptor, será a formação de agregados celulares, identificáveis através de citometria de fluxo com tripla marcação.

Para realização da tripla marcação, foram utilizados os anticorpos CD45-FITC, CD14-PE, e CD42a-PerCP. O CD45-FITC é utilizado para identificação dos leucócitos. O CD14-PE é utilizado para fazer a distinção entre as populações dos leucócitos (identifica os monócitos). O CD42a-PerCP é utilizado para a identificação das plaquetas (Ferraris et al., 1998). 
Antes da aquisição para avaliação da atividade do PAR-1, o citômetro foi calibrado com controles isotipos ( $\operatorname{lgG}_{1}-\mathrm{FITC}, \operatorname{lgG}_{2}-\mathrm{PE}, \lg _{1}-\mathrm{PerCP}$ ), e com controles positivos referentes aos anticorpos utilizados para a tripla marcação. A aquisição para avaliação da atividade foi feita com amplificação linear para os parâmetros FSC (tamanho dos eventos) e SSC (granulosidade dos eventos), (Figura 5, A), e na amplificação logarítmica para os parâmetros de fluorescência (Figura 5, B, C e D). Foram adquiridos 10.000 eventos dentro de uma janela de leitura para população de leucócitos. Esta janela de leitura foi feita baseando-se na distribuição dos leucócitos dentro dos eixos FSC e SSC. Para a análise da atividade pela formação de agregados plaqueta-leucócito (APL) foram feitos citogramas que continham na abscissa a distribuição de intensidade de fluorescência para o CD45 (todos os leucócitos) e na ordenada a distribuição de intensidade de fluorescência para o CD42a (plaquetas), (Figura 5, C). Esses citogramas foram divididos em 4 quadrantes de acordo com os controles isotipos e controles positivos, e a porcentagem dos eventos presentes no quadrante superior direito, em relação ao total de eventos adquiridos (10.000) foi avaliada. Como os eventos presentes no quadrante superior direito são positivos tanto para o CD45, quanto para o CD42a, foram considerados agregados plaqueta-leucócito (APL).

Para análise da atividade pela formação de agregados plaqueta-monócito (APM), foram feitos citogramas que continham na abscissa a intensidade de fluorescência para o CD42a, e na ordenada a intensidade de fluorescência para o CD14 (monócitos), (Figura 5, D). 


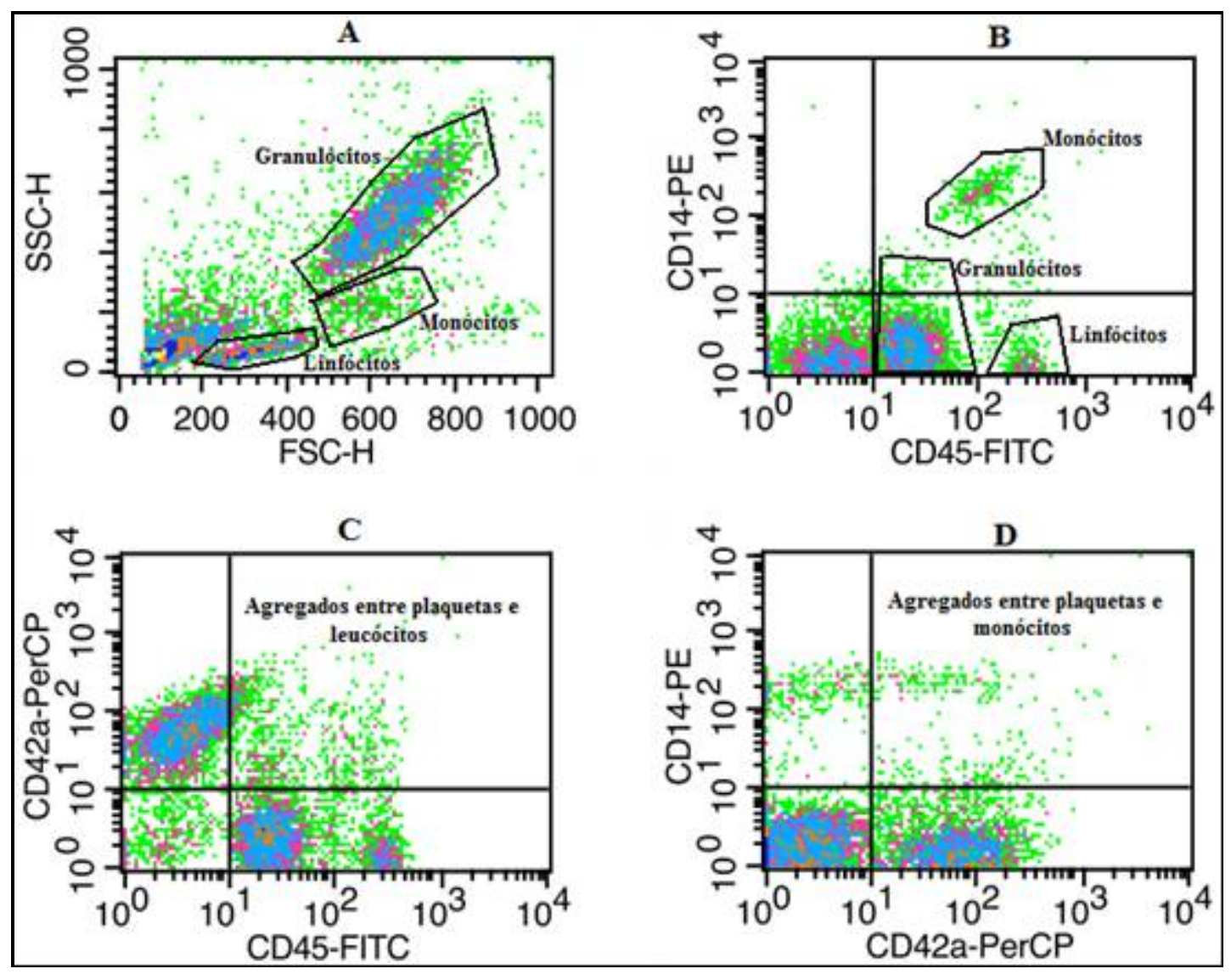

Figura 5 - Os citogramas de densidade A, B, C e D são representativos de um mesmo ensaio com tripla marcação, e sem estímulos. Estes citogramas foram obtidos com análise através do programa CellQuest. Foram adquiridos 10.000 eventos. Nos citogramas A e B as populações de leucócitos estão circundadas e identificadas. Em A, o tamanho dos eventos está representado na abscissa, e a granulosidade dos eventos está representada na ordenada. Em B, a intensidade de fluorescência para o CD45 está representada na abscissa, e a intensidade de fluorescência para o CD14 está representada na ordenada. Em C, a intensidade de fluorescência para o CD45 está representada na abscissa, e a intensidade de fluorescência para o CD42a está representada na ordenada. Contabilizando-se os eventos do quadrante superior direito, ou seja, os eventos positivos tanto para o CD45, quanto para o CD42a, obtém-se a porcentagem de agregados plaquetaleucócito (APL), em relação ao total de eventos adquiridos. Em $\mathbf{D}$, a intensidade de para fluorescência para o CD42a está representada na abscissa, e a intensidade de fluorescência para o CD14 está representada na ordenada. Contabilizando-se os eventos do quadrante superior direito, ou seja, os eventos positivos tanto para o CD14, quanto para o CD42a, obtém-se a porcentagem de agregados plaquetamonócito (APM), em relação ao total de eventos adquiridos. 
A porcentagem de APM foi dada pelo número de eventos com dupla positividade (positivos tanto para CD42a, quanto para CD14), em relação ao total de eventos adquiridos (10.000). A avaliação da formação de agregados no estado basal foi feita, empregando-se a mesma técnica descrita no item 4.5.2.2., porém, sem estímulos.

A Tabela 3, de maneira a complementar os dados da Figura 5, mostra as estatísticas apresentadas pelo programa CellQuest. Estas estatísticas são referentes aos citogramas C e D.

\begin{tabular}{|c|c|c|c|c|c|c|c|}
\hline \multicolumn{8}{|c|}{ Quadrant Statistics } \\
\hline \multicolumn{4}{|c|}{ File: 21)Doador s/estimulo.019 } & \multicolumn{4}{|c|}{ Log Data Units: Linear Values } \\
\hline \multicolumn{4}{|c|}{ Acquisition Date: 27-Aug-56 } & \multicolumn{4}{|c|}{$\begin{array}{l}\text { Log Data Units: LInear values } \\
\text { Gate: No Gate }\end{array}$} \\
\hline \multicolumn{4}{|c|}{ Gated Events: 10000} & \multicolumn{4}{|c|}{ Total Events: 10000} \\
\hline \multicolumn{4}{|c|}{ X Parameter: CD45-FITC (Log) } & \multicolumn{4}{|c|}{ Y Parameter: CD42a-PerCP (Log) } \\
\hline \multicolumn{8}{|c|}{ Quad Location: 10, 10} \\
\hline Quad & Events & $\%$ Gated & $\%$ Total & $X$ Mean & X Geo Mean & Y Mean & Y Geo Mean \\
\hline UL & 3799 & 37.99 & 37.99 & 4.12 & 3.58 & 65.10 & 54.35 \\
\hline UR & 850 & 8.50 & 8.50 & 93.47 & 36.27 & 125.98 & 57.93 \\
\hline LL & 512 & 5.12 & 5.12 & 2.70 & 2.22 & 3.25 & 2.52 \\
\hline LR & 4839 & 48.39 & 48.39 & 88.15 & 44.90 & 2.64 & 2.19 \\
\hline \multicolumn{8}{|c|}{ Quadrant Statistics } \\
\hline \multicolumn{4}{|c|}{ File: 21)Doador s/estimulo.019 } & \multicolumn{4}{|c|}{ Log Data Units: Linear Values } \\
\hline \multicolumn{4}{|c|}{ Acquisition Date: 27-Aug-56 } & \multicolumn{2}{|c|}{ Gate: No Gate } & & \\
\hline \multicolumn{4}{|c|}{ Gated Events: 10000} & \multicolumn{3}{|c|}{ Total Events: 10000} & \\
\hline \multirow{2}{*}{\multicolumn{4}{|c|}{$\begin{array}{l}\text { X Parameter: CD42a-PerCP (Log) } \\
\text { Quad Location: } 10,10\end{array}$}} & \multicolumn{4}{|c|}{ Y Parameter: CD14-PE (Log) } \\
\hline & & & & & & & \\
\hline Quad & Events & $\%$ Gated & $\%$ Total & $\mathrm{X}$ Mean & X Geo Mean & Y Mean & Y Geo Mean \\
\hline UL & 262 & 2.62 & 2.62 & 3.24 & 2.49 & 189.63 & 153.41 \\
\hline UR & 295 & 2.95 & \begin{tabular}{|l|}
2.95 \\
\end{tabular} & 175.82 & 63.30 & 254.03 & 65.10 \\
\hline LL & 5070 & 50.70 & 50.70 & 2.65 & 2.19 & 2.09 & 1.78 \\
\hline LR & 4373 & 43.73 & 43.73 & 69.23 & 54.07 & 1.84 & 1.53 \\
\hline
\end{tabular}

Tabela 3 - Dados estatísticos fornecidos pelo programa CellQuest referentes aos citogramas $\mathbf{C}$ e $\mathbf{D}$ da Figura 5 . O valor de porcentagem de agregados plaqueta-leucócito (APL) está representado em azul, e agregados plaqueta-monócito (APM) está representado em vermelho. 


\subsubsection{Atividade do PAR-1 mediante estímulo proteolítico}

Alíquotas de $30 \mu \mathrm{l}$ de sangue total foram incubadas por 5 minutos com GPRP (concentração final $2 \mathrm{mM}$ ), em seguida foi realizada uma estimulação por 10 minutos com a adição de trombina (concentração final $2 \mathrm{U} / \mathrm{ml}$ ). Foram então adicionados os anticorpos CD45-FITC, CD14-PE e CD42a-PerCP seguindo-se incubação por 30 minutos no escuro a $4^{\circ} \mathrm{C}$. Esta temperatura é importante para interromper a atividade das células após estímulo, e a internalização dos receptores. Após a incubação, as hemácias foram lisadas com a adição de $1 \mathrm{~mL}$ de tampão de lise FACS, homogeneização, e nova incubação por 10 minutos em temperatura ambiente, seguindo-se lavagem com a adição de $2 \mathrm{ml}$ de tampão FACS, e centrifugação por 10 minutos a 1200xg. Após a lavagem, o sobrenadante foi descartado e o sedimento ressuspendido com $200 \mu \mathrm{l}$ de tampão FACS e fixado com igual volume de PFA gelado (concentração final de 1\%), (Ferraris et al., 1998; Poullis et al., 2000). As amostras foram mantidas no escuro e a $4^{\circ} \mathrm{C}$, seguido de aquisição no citômetro em até 24 horas.

\subsubsection{Atividade do PAR-1 mediante estímulo não proteolítico}

Alíquotas de $30 \mu \mathrm{l}$ de sangue total foram estimuladas por 10 minutos em temperatura ambiente com a adição de SFLLRN (concentração final $12 \mu \mathrm{M}$ ). Foram então adicionados os anticorpos anti-CD45-FITC, CD14-PE e CD42a-PerCP, seguindo-se incubação por 30 minutos no escuro a $4^{\circ} \mathrm{C}$. Após a incubação, as hemácias foram lisadas com a adição de $1 \mathrm{~mL}$ de tampão de lise FACS, e as amostras incubadas por 10 minutos em 
temperatura ambiente, seguindo-se como descrito anteriormente (4.5.2.1). As amostras foram mantidas no escuro e a $4^{\circ} \mathrm{C}$, seguido de aquisição no citômetro em até 24 horas.

\subsubsection{Avaliação da expressão da selectina-P (CD62P) das} plaquetas no estado basal e após estimulação

A selectina-P é um componente dos grânulos alfa das plaquetas em repouso, e é translocada para a superfície das plaquetas somente após estimulação. A selectina-P é mediadora da adesão de plaquetas ativadas à neutrófilos e monócitos e sua expressão foi determinada utilizando-se o anticorpo anti-CD62P marcado com PE, e controle isotipo de camundongo $\lg \mathrm{G}_{1}$ marcado com $\mathrm{PE}$.

A expressão de selectina-P plaquetária foi realizada utilizando-se alíquotas de $5 \mu \mathrm{l}$ de sangue total estimuladas com TRAP (concentração final $60 \mu \mathrm{M})$ por 5 minutos em temperatura ambiente. Em seguida foi adicionado o anticorpo CD62P ou controle isotipo, seguido de incubação por 30 minutos em temperatura ambiente, e seguiu-se como descrito em 4.5.1.1.

\subsection{Análise estatística}

As variáveis envolvidas no estudo foram testadas com relação à sua aderência à distribuição normal, sendo então os resultados expressos em média e desvio-padrão (aderência satisfatória) ou mediana e limites (não aderência). Quando foi possível obter aderência satisfatória após a transformação logarítmica, a análise estatística foi conduzida com uso de 
procedimentos paramétricos. Em caso contrário, a opção recaiu sobre o uso de procedimentos não paramétricos.

Em situações onde se teve que recorrer a procedimentos não paramétricos, as comparações entre pacientes e controles foram feitas com uso do teste de Mann-Whitney, e as comparações entre duas condições de estudo, no mesmo indivíduo, com uso do teste de Wilcoxon.

As comparações entre pacientes e controles envolvendo mais de uma condição experimental no mesmo indivíduo foram feitas com uso de análise de variância para dois fatores (grupos, pacientes vs. controles, e condições experimentais) com medidas repetidas de um deles (condições experimentais). Havendo diferenças globais significantes em relação a algum desses fatores, as múltiplas comparações foram feitas com o uso do teste de Tukey-Kramer.

A possível influência de uma variável ou de variáveis sobre uma outra, foi verificada com uso de regressão linear simples ou múltipla, sendo a variável resposta sempre testada (na forma original ou após transformação) em condição de aderência adequada à distribuição normal.

Em todos os procedimentos, adotou-se 0,05 como nível de significância. 
RESULTADOS 


\section{RESULTADOS}

Todos os resultados obtidos (valores de IFM das plaquetas positivas, a porcentagem de plaquetas positivas, e as porcentagens de agregados plaqueta-leucócito, e agregados plaqueta-monócito), encontram-se individualmente discriminados no item 8 (Anexos).

\subsection{Pacientes}

Trinta pacientes foram incluídos no estudo, sendo oito do sexo masculino e vinte e dois do sexo feminino, com idade variando de 11 a 78 anos (mediana de 50 anos), e pressão sistólica da artéria pulmonar (ecocardiograma) de $89 \pm 29 \mathrm{mmHg}$ (média \pm D.P.), sendo considerado o valor inferior a $40 \mathrm{mmHg}$ como normal. Dentre os pacientes estudados, 28 eram portadores de HAP associada a cardiopatias congênitas, e 2 eram portadores de HAP idiopática. A contagem de plaquetas circulantes variou de 53 a $389 \times 10^{3} / \mu \mathrm{l}$ (mediana de $190 \times 10^{3} / \mu \mathrm{l}$ ), e em 9 pacientes o número situou-se abaixo do limite inferior de normalidade, considerado como $150 \mathrm{x}$ $10^{3} / \mu \mathrm{l}$. O valor do hematócrito variou de 28 a $69 \%$ (mediana de $49 \%$ ), e esteve superior a $50 \%$ em 12 dos 30 pacientes estudados. Todos os pacientes encontravam-se clinicamente estáveis, em acompanhamento ambulatorial, e sem uso de medicação que pudesse interferir com a função plaquetária. Os medicamentos em uso (e que, portanto não poderiam ser 
suspensos) foram a digoxina, a furosemida, a hidroclorotiazida, e a varfarina. Os dados demográficos, o diagnóstico, a pressão arterial pulmonar, o hematócrito, e a contagem de plaquetas encontram-se na Tabela 4.

Tabela 4 - Dados diagnósticos e laboratoriais

\begin{tabular}{|c|c|c|c|c|c|c|c|}
\hline No. & Identificação & Sexo & $\begin{array}{l}\text { Idade } \\
\text { (anos) }\end{array}$ & Diagnóstico & $\begin{array}{c}\text { PSAP } \\
(\mathrm{mmHg})\end{array}$ & $\mathrm{Ht}(\%)$ & $\begin{array}{c}\text { Plaquetas } \\
\left(\times 10^{3} / \mu \mathrm{l}\right)\end{array}$ \\
\hline 01 & A I & M & 28 & DSAV & 90 & 69 & 53 \\
\hline 02 & J A N & $\mathrm{F}$ & 50 & $S / C^{*}$ & 127 & 51 & 102 \\
\hline 03 & I D F & $\mathrm{F}$ & 56 & CIA & 90 & 56 & 109 \\
\hline 04 & G S M & $\mathrm{M}$ & 51 & $\mathrm{ClA}$ & 60 & 53 & 192 \\
\hline 05 & MGS & $\mathrm{F}$ & 26 & $\mathrm{CIA}$ & 130 & 59 & 188 \\
\hline 06 & HS Q & $\mathrm{F}$ & 48 & $\mathrm{CIA}$ & 130 & 49 & 134 \\
\hline 07 & $C E C$ & $\mathrm{~F}$ & 27 & DSAV & 78 & 55 & 158 \\
\hline 08 & M A O & $\mathrm{F}$ & 70 & $\mathrm{ClA}$ & 73 & 34 & 144 \\
\hline 09 & C M V & $\mathrm{F}$ & 60 & CIA & 107 & 57 & 212 \\
\hline 10 & QNS & $\mathrm{F}$ & 46 & CIA & 50 & 58 & 234 \\
\hline 11 & MP S & $\mathrm{F}$ & 41 & CIA/DAVP & 141 & 30 & 389 \\
\hline 12 & GD N & $M$ & 38 & DSAV & 110 & 56 & 171 \\
\hline 13 & G C C & $\mathrm{F}$ & 52 & CIA/DAVD & 90 & 35 & 257 \\
\hline 14 & A S C & $\mathrm{F}$ & 52 & CIA & 100 & 49 & 208 \\
\hline 15 & O G T & $M$ & 58 & $\mathrm{CIA}$ & 41 & 44 & 179 \\
\hline 16 & CAP & $\mathrm{F}$ & 47 & CIA/DAVP & 50 & 43 & 249 \\
\hline 17 & E A R & $\mathrm{F}$ & 60 & CIA & 72 & 46 & 124 \\
\hline 18 & L J S & $M$ & 78 & CIA & 67 & 37 & 84 \\
\hline 19 & VSS & $\mathrm{F}$ & 69 & CIA & 75 & 49 & 78 \\
\hline 20 & M R S & $\mathrm{F}$ & 61 & CIA & 50 & 49 & 317 \\
\hline 21 & $\mathrm{JAN}$ & $M$ & 58 & CIA & 75 & 54 & 174 \\
\hline 22 & $H N Q$ & $\mathrm{~F}$ & 18 & CIV & 85 & 45 & 271 \\
\hline 23 & EOS & $\mathrm{F}$ & 51 & CIV/PCA & 145 & 64 & 160 \\
\hline 24 & I C & $\mathrm{F}$ & 49 & CIA & 56 & 43 & 231 \\
\hline 25 & O L J & $M$ & 57 & DSAV & 85 & 46 & 283 \\
\hline 26 & MDS & $\mathrm{F}$ & 42 & CIA & 72 & 45 & 254 \\
\hline 27 & G B S & $M$ & 11 & $S / C^{*}$ & 118 & 49 & 225 \\
\hline 28 & $A C C$ & $\mathrm{~F}$ & 21 & CIV & 115 & 53 & 215 \\
\hline 29 & RTF & $\mathrm{F}$ & 39 & CIA & 122 & 28 & 66 \\
\hline 30 & $M \vee P$ & $\mathrm{~F}$ & 55 & CIA & 70 & 43 & 254 \\
\hline
\end{tabular}




\subsection{Avaliação da expressão do PAR-1}

A expressão do PAR-1 foi analisada por citometria de fluxo usando os anticorpos monoclonais SPAN12, e ATAP2.

\subsubsection{Receptores íntegros (SPAN12)}

O estudo dos receptores íntegros utilizando o anticorpo SPAN12, e avaliado através da porcentagem dos eventos positivos $(\%+)$ não apresentou diferença estatisticamente significante entre pacientes e controles, com valores em mediana e limites de 42\% (21 a 85\%) e 44\% (25 a $66 \%$ ), respectivamente, $p=0,2$, Figura 6 .

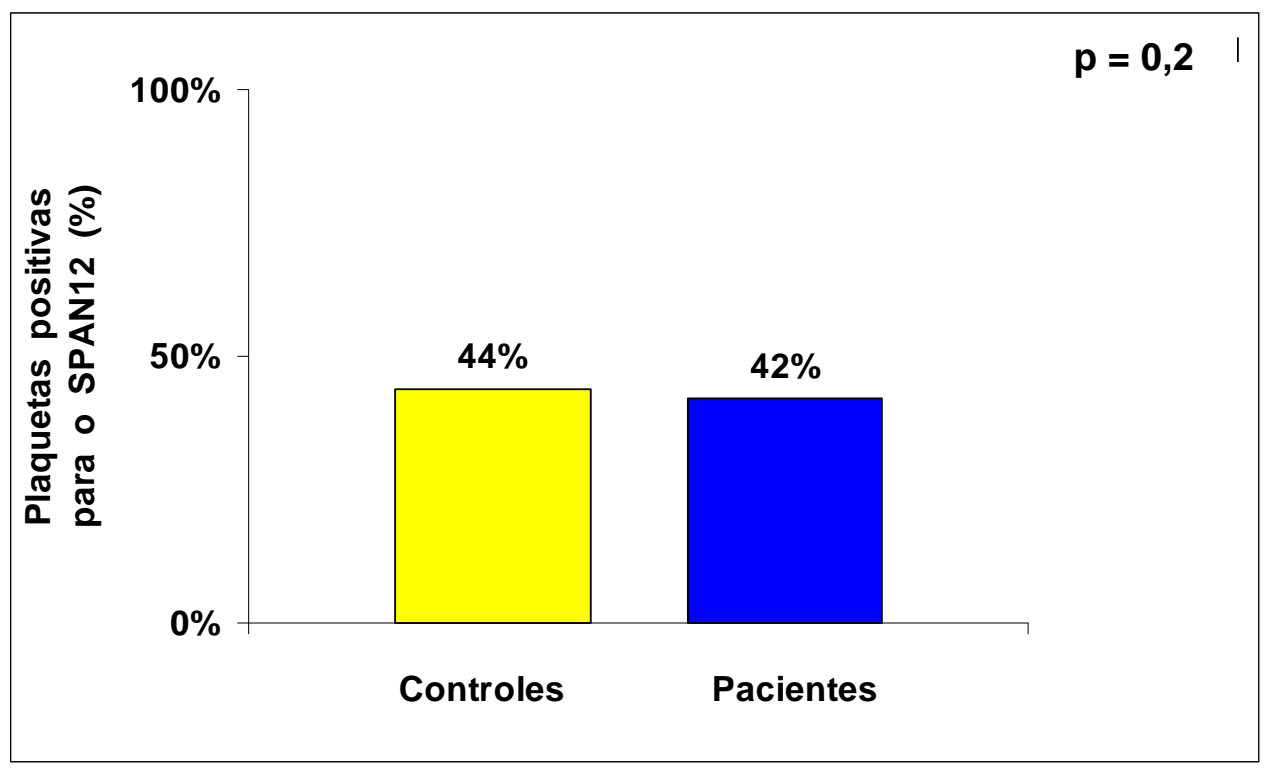

Figura 6 - Reatividade ao anticorpo SPAN12, expressa como porcentagem de plaquetas positivas, comparativamente entre pacientes (azul) e controles (amarelo). Resultados apresentados em mediana da porcentagem das plaquetas positivas para o anticorpo SPAN12 (PAR-1 íntegro) em relação ao total de eventos adquiridos (10.000). A diferença encontrada não teve valor estatisticamente significante $(p=0,2)$. 
Entretanto, a expressão de PAR-1 íntegro, quando avaliada pela intensidade de fluorescência média (IFM) das plaquetas positivas, apresentou ligeiro aumento estatisticamente significante entre pacientes e controles, com valores em mediana e limites de 15,73 (10,63 a 41,21) e 13,35 (9,88 a 25,5), respectivamente, $p=0,02$, Figura 7. Embora o valor correspondente à IFM dos pacientes tenha sido discretamente superior ao valor encontrado nos controles, com significância estatística, consideramos a magnitude desta diferença pequena sob o ponto de vista biológico.

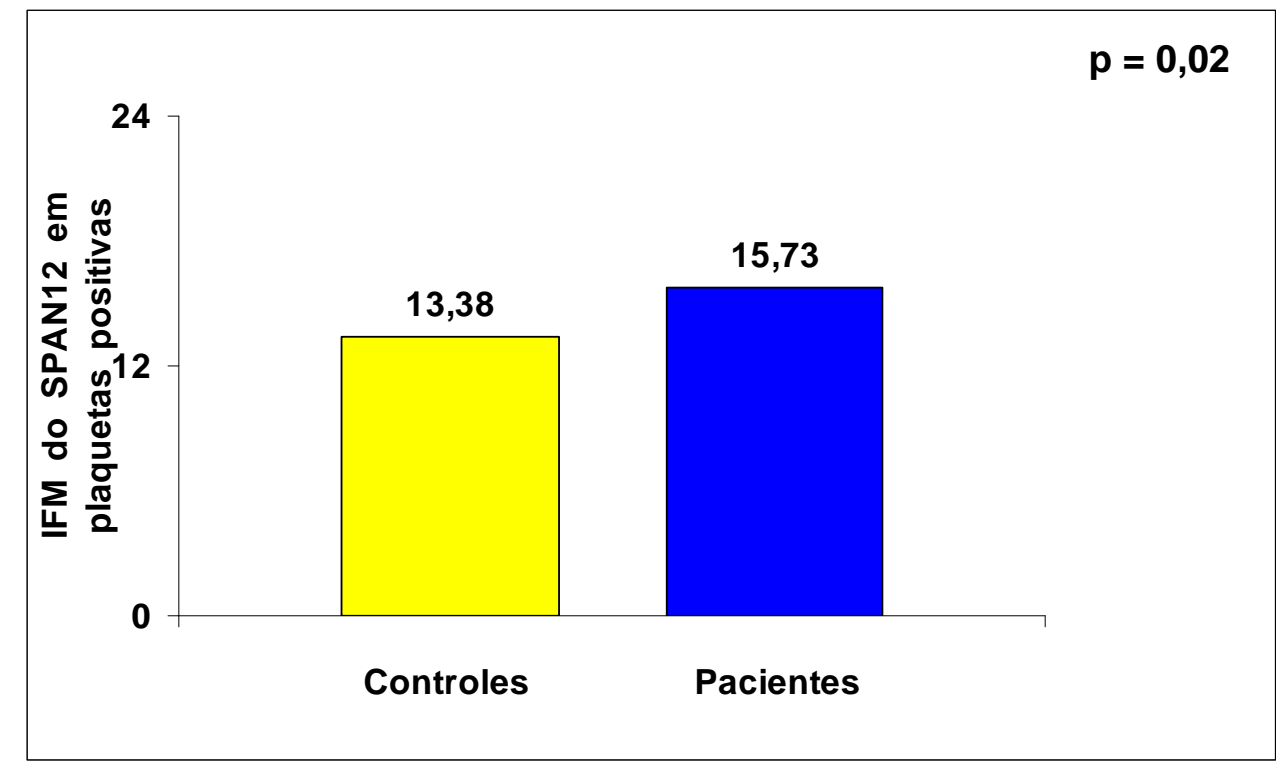

Figura 7 - Reatividade ao anticorpo SPAN12, expressa como intensidade de fluorescência de plaquetas positivamente marcadas, comparativamente entre pacientes (azul) e controles (amarelo). Resultados apresentados em mediana da IFM (intensidade de fluorescência média) das plaquetas positivas para o anticorpo SPAN12 (PAR-1 íntegro). Foi encontrada diferença estatisticamente significante com ligeiro aumento da expressão de PAR-1 íntegro (SPAN12) nos pacientes em relação aos controles $(p=0,02)$. 


\subsubsection{Receptores íntegros e clivados (ATAP2)}

Estudando-se os receptores íntegros e clivados (anticorpo ATAP2), e analisando-os pela porcentagem de plaquetas positivas, foi observada uma diminuição estatisticamente significante das plaquetas positivas para o ATAP2 nos pacientes em relação aos controles. Valores em mediana e limites de $77 \%$ (38 a 93\%) e $82 \%$ (57 a 94\%), respectivamente, $p=0,01$, Figura 8.

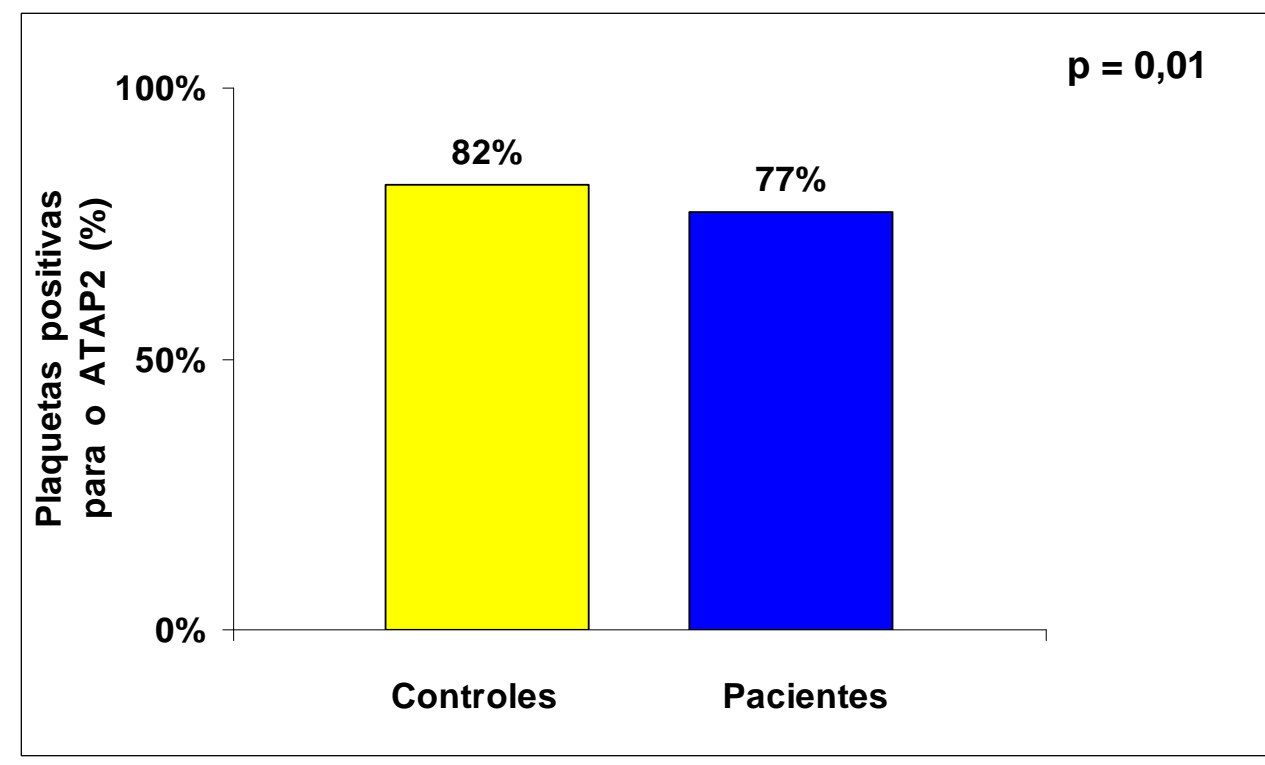

Figura 8 - Reatividade ao anticorpo ATAP2, expressa como porcentagem de plaquetas positivas, comparativamente entre pacientes (azul) e controles (amarelo). Resultados apresentados em mediana da porcentagem das plaquetas positivas para 0 anticorpo ATAP2 (receptores íntegros e clivados), em relação ao total de eventos adquiridos (10.000). Foi observada diminuição da expressão de PAR-1 íntegro e clivado (ATAP2) nos pacientes em relação aos controles com valor estatisticamente significante $(p=0,01)$.

A expressão do PAR-1 independente de clivagem (anticorpo ATAP2) quando avaliada através da intensidade de fluorescência média das plaquetas positivas, não apresentou diferença com significância estatística 
nos pacientes em relação aos controles. Valores em mediana e limites de $37,75(16,05$ a 178,2$)$ e $31,53(15,76$ a 142,98$)$, respectivamente, $p=0,2$, Figura 9.

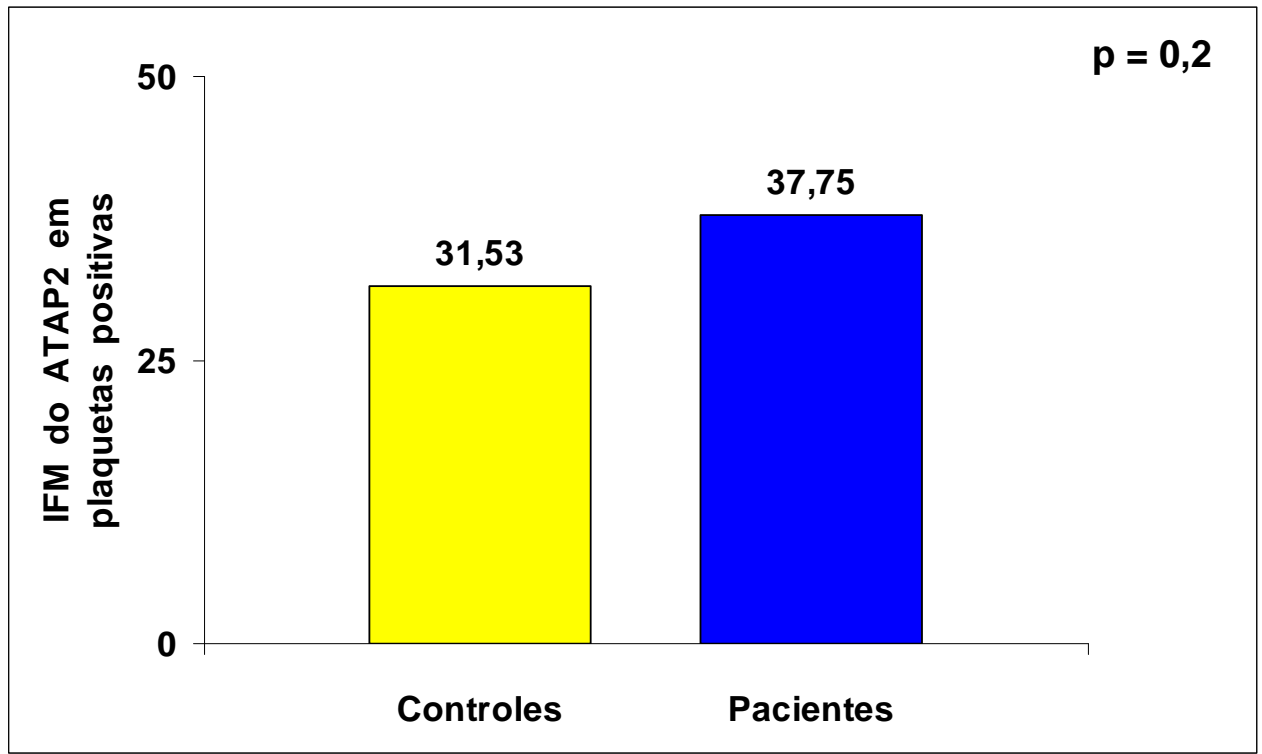

Figura 9 - Reatividade ao anticorpo ATAP2, expressa como a intensidade de fluorescência em plaquetas positivamente marcadas, comparativamente entre pacientes (azul) e controles (amarelo). Resultados apresentados em mediana da IFM (intensidade de fluorescência média) das plaquetas positivas para o anticorpo ATAP2 (PAR-1 íntegro e clivado). A diferença encontrada entre pacientes e controles, não teve valor estatisticamente significante $(p=0,2)$.

\subsection{Avaliação da atividade do PAR-1}

A atividade funcional do PAR-1 foi estudada por citometria de fluxo, através de ensaios de estimulação (induzidos por trombina, ou SFLLRN). O resultado final do estímulo do PAR-1 foi a formação de agregados envolvendo plaquetas e leucócitos, que foram identificados por tripla marcação com CD45-FITC (identifica leucócitos, sem especificar), CD14-PE (identifica monócitos), e CD42a-PerCP (identifica plaquetas). 


\subsubsection{Formação de agregados plaqueta-leucócito (APL)}

Em termos de formação de agregados plaqueta-leucócito (APL) no estado basal em relação às condições de estimulação, houve aumento estatisticamente significante tanto no grupo de pacientes como no grupo controle ( $p<0,01$ para ambos). Entretanto, não foram encontradas diferenças estatisticamente significantes na comparação entre os dois grupos $(p=0,2)$, Figura 10 .

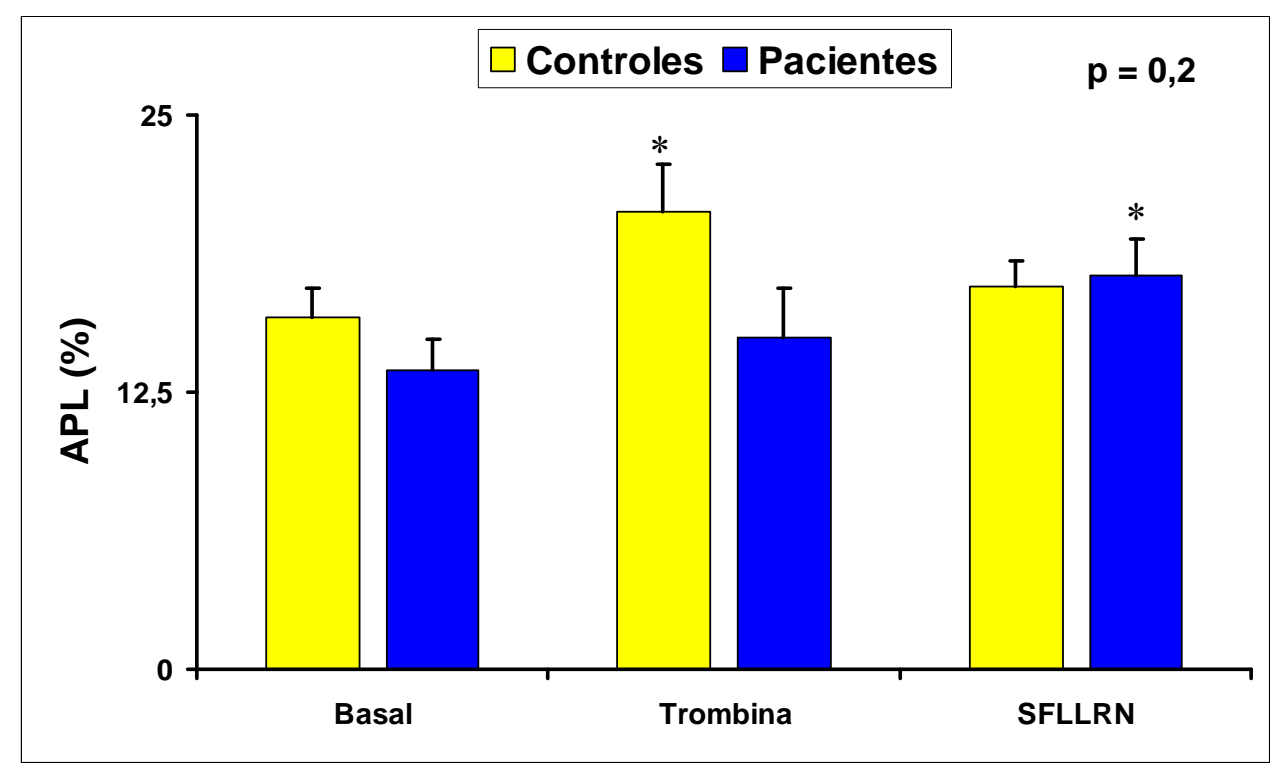

Figura 10 - Formação de agregados plaqueta-leucócito (APL) em condições experimentais (basal sem estímulo, estímulo proteolítico por trombina, e estímulo não proteolítico por SFLLRN) em pacientes (azul) e controles (amarelo). Resultados apresentados em média e erro padrão da porcentagem de formação de APL em relação ao total de eventos adquiridos (10.000). Agregados plaqueta-leucócito (APL), foram caracterizados por eventos com dupla positividade, ou seja, eventos positivos tanto para CD42a-PerCP (plaquetas), quanto para CD45-FITC (leucócitos). Em relação à condição basal, após estimulação houve aumento da formação de APL tanto no grupo controle, quanto no grupo de pacientes com valor estatisticamente significante $(p<0,01)$. Entretanto, não houve diferença significante quando comparados o grupo de pacientes com o grupo controle $(p=0,2) \cdot\left({ }^{*}\right)$ corresponde à significância estatística $(p<0,05)$ da condição de estimulação versus basal, por teste de multicomparação após ANOVA. 
Na resposta à estimulação com a formação de APL, foi observado comportamento diferenciado no grupo de pacientes em relação ao grupo controle, nos seguintes aspectos:

a) os pacientes responderam ao estímulo induzido por SFLLRN (um agente capaz de estimular PAR-1 independentemente de seu estado, íntegro ou clivado) com aumento da formação de APL em relação ao estado basal $(p<0,05)$;

b) em indivíduos normais, houve resposta quando os receptores íntegros foram estimulados por trombina, ou seja, houve aumento da formação de APL em relação ao estado basal $(p<0,05)$.

\subsubsection{Formação de agregados plaqueta-monócito (APM)}

Em termos de formação de agregados plaqueta-monócito (APM) no estado basal em relação às condições de estimulação, foram encontradas diferenças estatisticamente significantes no grupo de pacientes e no grupo controle $(p<0,0001)$. Entretanto, não foram encontradas diferenças estatisticamente significantes na comparação entre os dois grupos $(p=0,4)$, Figura 11

Na resposta à estimulação com a formação de APM, foi observado comportamento semelhante no grupo de pacientes e no grupo controle, nos seguintes aspectos:

a) no grupo controle após estimulação por trombina dos receptores íntegros, foi observado aumento estatisticamente significante da formação 
de APM em relação ao estado basal, e o mesmo fato ocorreu no grupo de pacientes (respectivamente, $p<0,01$ e $p<0,01$ );

b) tanto no grupo controle, quanto no grupo de pacientes, a estimulação por SFLLRN (agente capaz de estimular PAR-1 independente de seu estado, íntegro ou clivado) foi ineficiente no sentido de aumentar a formação de APM em relação ao estado basal.

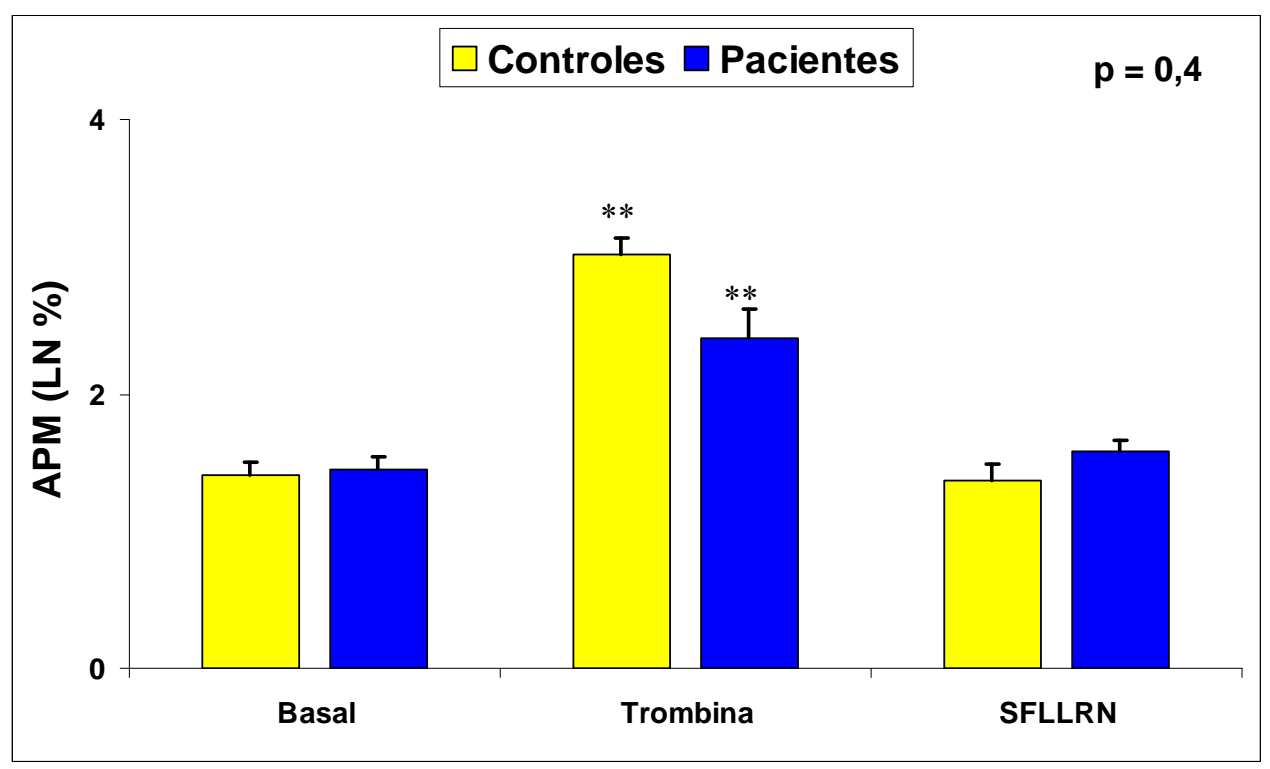

Figura 11 - Formação de agregados plaqueta-monócito (APM) em condições experimentais (basal sem estímulo, estímulo proteolítico por trombina, e estímulo não proteolítico por SFLLRN) em pacientes (azul) e controles (amarelo). Resultados apresentados em média e erro padrão da transformação em logarítmos naturais (LN) da porcentagem de formação de APM em relação ao total de eventos adquiridos (10.000). Agregados plaqueta-monócito (APM), foram caracterizados por eventos com dupla positividade, ou seja, eventos positivos tanto para CD42a-PerCP (plaquetas), quanto para CD14-PE (monócitos). Em relação à condição basal, após estimulação houve aumento da formação de APM com valores estatisticamente significantes tanto no grupo de pacientes, como no grupo controle ( $p<0,01$ para ambos). Entretanto, não houve diferença significante quando comparados o grupo de pacientes com o grupo controle $(p=0,4) .\left({ }^{* *}\right)$ corresponde à significância estatística $(p<0,01)$ da condição de estimulação versus basal, por teste de multicomparação após ANOVA. 
5.4. Avaliação da expressão da selectina-P (CD62P) das plaquetas no estado basal e após estimulação

As plaquetas de controles e pacientes foram analisadas no estado basal e após estimulação com TRAP $(60 \mu \mathrm{M})$, quanto à expressão de selectina-P de membrana plaquetária avaliada com a marcação pelo anticorpo anti-CD62P-PE. Observou-se pela análise dos dados apresentados na Figura 12, que tanto nas plaquetas de pacientes, quanto de indivíduos normais, a estimulação por TRAP resultou em aumento estatisticamente significante da expressão em membrana de selectina-P ( $p<0,0001$ para ambos), porém não houve diferenças significantes quando foram feitas comparações entre pacientes e controles $(p=0,9)$.

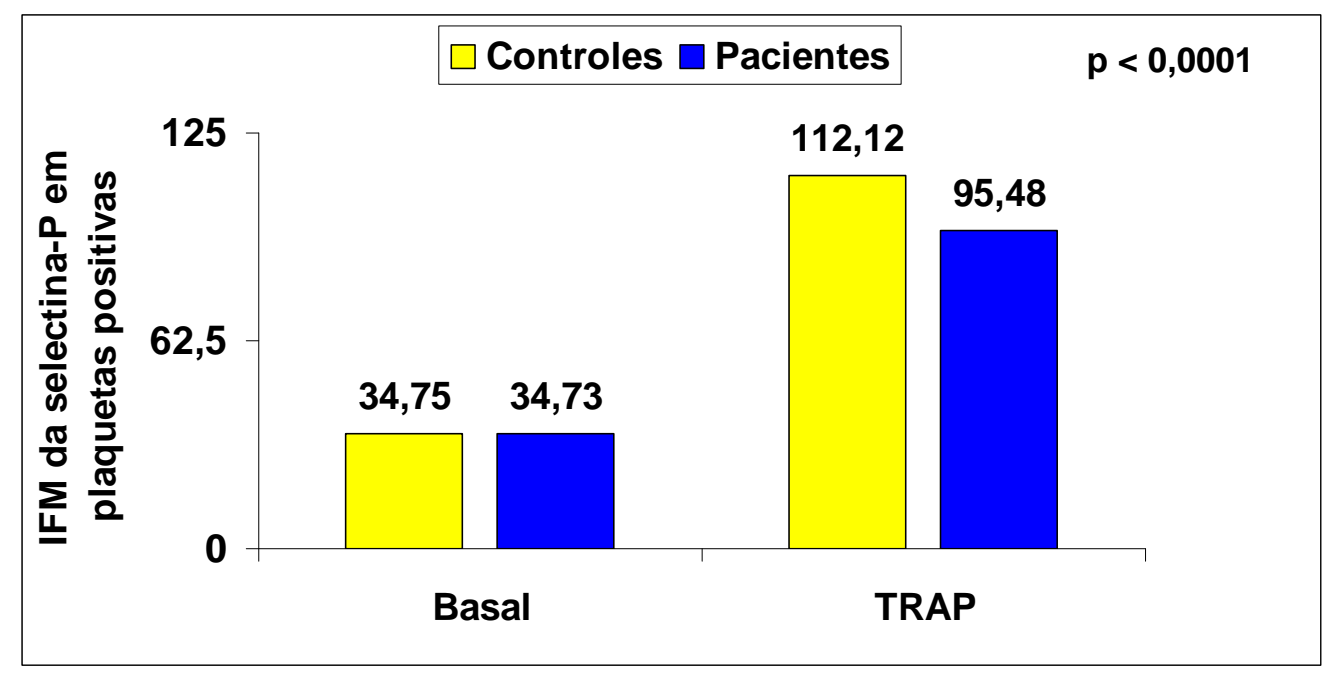

Figura 12 - Expressão de selectina-P de membrana plaquetária no estado basal vs. estimulação por TRAP entre pacientes (azul) e controles (amarelo). Resultados apresentados em mediana da IFM das plaquetas positivas. A expressão de selectina-P induzida por estímulo (TRAP) foi estatisticamente maior quando comparada com a expressão de selectina- $P$ na condição basal, sendo válido tanto para o grupo de pacientes, quanto para o grupo controle, e o valor de significância estatística foi de $p<0,0001$ para ambos. 


\subsection{Atividade do PAR-1 e eventos correlacionados}

Entre os eventos que foram correlacionados com a formação de APL ou APM mediante estímulo proteolítico (trombina) estavam a expressão de PAR-1 íntegro (anticorpo SPAN12), avaliada tanto pela IFM das plaquetas positivas, quanto pela porcentagem de plaquetas positivas, o hematócrito, e a contagem de plaquetas. Entretanto, em nenhuma das situações foram encontradas correlações estatisticamente significantes.

Também não foi encontrada correlação, com significância estatística, da formação de APL e APM após estímulo não proteolítico (SFLLRN) com a expressão de PAR-1 independente de clivagem (anticorpo ATAP2), avaliada tanto pela IFM das plaquetas positivas, quanto pela porcentagem de plaquetas positivas, o hematócrito, e a contagem de plaquetas.

Com relação à expressão de selectina-P de membrana da plaqueta após estímulo (TRAP), também não foi encontrada significância estatística na correlação com a formação de APL ou APM induzidos por estímulos. 
DISCUSSÃO

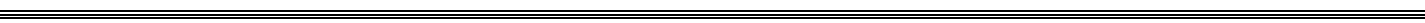




\section{DISCUSSÃO}

Tem sido amplamente estudada a função plaquetária em pacientes com hipertensão arterial pulmonar. Muitas investigações foram feitas com testes funcionais, que refletem a estimulação das plaquetas, medindo-se os produtos de secreção como a $\beta$-tromboglobulina, o tromboxano B2 e o fator 4 plaquetário (Maeda et al., 2005; Eddahibi et al., 2001). O presente trabalho se dedicou ao estudo de antígenos dependentes de ativação, em plaquetas e leucócitos circulantes. Devido à grande importância do receptor de trombina (PAR-1) na fisiologia das células, este trabalho teve como finalidade estudar sua expressão e atividade, induzida por três diferentes agonistas, além da expressão de selectina-P de superfície plaquetária, que é uma proteína de adesão altamente recrutadora de leucócitos.

Os testes foram realizados por citometria de fluxo, principalmente para estudar as plaquetas em seu meio mais próximo do biológico, e também porque entre os pacientes estudados, $40 \%$ tinham o nível de hematócrito acima de $50 \%$, e $30 \%$ apresentaram número de plaquetas inferior a $150 \times 10^{3} / \mu$ l (valor considerado normal até $45 \%$ para o hematócrito e de $150 \times 10^{3}$ a $400 \times 10^{3} / \mu$ l para as plaquetas). Sendo que nestas condições, a separação das plaquetas por centrifugação torna-se muito difícil.

Analisando-se a expressão de PAR-1 plaquetário nos pacientes com hipertensão arterial pulmonar, foram utilizados dois anticorpos, o SPAN12 que reconhece somente o receptor íntegro, e o ATAP2 que reconhece tanto 
o receptor íntegro quanto a sua fração clivada (Brass et al., 1994). Observou-se expressão semelhante de PAR-1 íntegro em pacientes e controles, sugerindo que os receptores plaquetários dos dois grupos têm a mesma capacidade de resposta à trombina, mesmo quando gerada "in vivo". A diminuição da expressão do PAR-1 clivado, nos pacientes em relação aos controles, indica que houve um processo de internalização, pois o clone ATAP2 reconhece tanto o PAR-1 íntegro quanto a sua fração clivada, porém não a sua fração internalizada (Brass et al., 1994).

Recentemente, foi descoberto um polimorfismo do PAR-1 na membrana da plaqueta capaz de afetar sua expressão (Ramström et al., 2008). No referido estudo, foi observada uma alteração na densidade do PAR-1, que foi correlacionada com a magnitude de resposta plaquetária ao peptídeo SFLLRN analisada tanto por técnicas de agregação plaquetária, quanto por citometria de fluxo, e comparada com a expressão de selectina-P de superfície e ativação da integrina $\alpha_{\| b} \beta_{3}$. Além disto, o mesmo trabalho demonstrou que plaquetas de indivíduos normais apresentam concentrações variadas de PAR-1. Estes resultados indicam que a semelhança de expressão de PAR-1 plaquetário, em pacientes e controles que foi observada no presente trabalho, pode ter sido influenciada pela variação intrínseca existente nos grupos estudados (pacientes e controles).

Considerando-se que a expressão de receptores íntegros é semelhante em plaquetas de pacientes comparativamente aos controles, a característica de resposta observada pela formação de agregados entre plaquetas e leucócitos, poderia sugerir diferenças em PAR-1 situado em outros 
elementos figurados (leucócitos), ou, alternativamente, diferenças nos processos de sinalização necessários para a formação de agregados, processos esses, independentes da integridade de receptores. Agregados entre plaquetas e leucócitos circulantes têm sido usados como marcadores de ativação plaquetária endógena (Furman et al., 1998; Elalamy et al., 2008) Em contraste com nossas expectativas, não foi encontrado aumento no número desses agregados nos pacientes estudados. Uma possível explicação seria a rápida remoção dos agregados formados, através da circulação pulmonar.

Em relação a leucócitos (independente do tipo), pacientes parecem responder ao SFLLRN, capaz de estimular PAR-1 independentemente do seu estado, íntegro ou clivado, enquanto que em indivíduos normais, a resposta ocorre especialmente quando o receptor íntegro é estimulado (trombina). Os monócitos e linfócitos expressam PAR-1, e a estimulação por trombina ou SFLLRN é capaz de ativá-los, pois ocorre aumento da concentração de cálcio intracelular, e indução de síntese e secreção de citocinas (Crago et al., 1995; Lippuner et al., 2007). Sendo assim, as diferenças observadas podem ter sido influenciadas pela integridade de receptores de trombina presentes em linfócitos e monócitos, afetando assim a formação de agregados entre plaquetas e leucócitos.

Muitos epítopos de membrana têm sido usados como marcadores de ativação plaquetária endógena em doenças vasculares (Samara e Gurbel, 2003). Dentre eles, encontram-se os receptores de fibrinogênio e vitronectina (integrinas $\alpha$ llb $\beta 3$ e $\alpha v \beta 3$, respectivamente), e a selectina-P 
(CD62P). A selectina-P é uma das principais moléculas envolvidas na ligação das plaquetas com os leucócitos (Dore, 1998; McEver, 2001). Nas plaquetas em repouso (não ativadas), a selectina-P é armazenada nos grânulos $\alpha$, porém após ativação e degranulação, passa a ser expressa na membrana das plaquetas (Johnston et al., 1989). Foi mostrado que na doença arterial coronariana crônica existe aumento da porcentagem de plaquetas degranuladas circulantes que expressam selectina-P (Furman et al., 1998). Entretanto, estas plaquetas rapidamente liberam a selectina-P da superfície para o plasma, continuam circulando e funcionando (Michelson et al., 1996). Nos pacientes estudados, de maneira semelhante aos controles, a estimulação plaquetária por TRAP, promoveu a expressão em superfície de selectina-P. Isto sugere que as plaquetas dos pacientes não são refratárias à liberação de seu conteúdo granular, e encontram-se aptas a responder aos estímulos, tanto quanto as plaquetas de controles.

Os dados gerados pelo presente estudo, não permitem afirmar diferenças relevantes entre plaquetas de pacientes com HAP, e de indivíduos controles quanto às características de expressão e funcionalidade do receptor de trombina (PAR-1), e à expressão induzida de selectina-P. As pequenas diferenças observadas com relação ao PAR-1 poderiam estar relacionadas a outros elementos celulares onde o receptor também é expresso. Assim sendo, sob o ponto de vista do receptor de trombina e da selectina-P, as plaquetas desses pacientes são potencialmente estimuláveis. Em outras palavras, com base estritamente dos achados deste estudo, não há razões para se acreditar que as plaquetas presentes no sangue periférico 
desses pacientes estejam "exauridas", portanto, incapazes de responder a estímulos. Especulativamente, os achados nos levariam a acreditar que a terapêutica por agentes inibidores da função plaquetária continua tendo relevância nesta doença.

Em conclusão, durante os últimos anos, houve um significante avanço na compreensão dos mecanismos de ativação, sinalização e agregação plaquetária (Coppinger et al., 2007, Barrett et al., 2008; Kleiman et al., 2008; Patel-Hett et al., 2008). Nosso atual conhecimento reconhece as contribuições simultâneas de múltiplos, e independentes caminhos de sinalização da ativação plaquetária, os quais, a relativa importância parece diferir dependendo do modelo experimental analisado, e das condições nas quais as interações plaquetárias ocorrem. Além do mais, o que aparentemente parece ser um campo confuso, com resultados contraditórios, deve na verdade, refletir a grande versatilidade de um importante sistema biológico, que deve ser capaz de operar de forma eficiente, em diversas condições fisiológicas e patológicas, para preencher seu papel essencial na hemostasia. 


\section{CONCLUSÕES}

Após análise do presente trabalho, foi concluído que nos pacientes em relação aos controles, não houve diferenças estatisticamente significantes na expressão de PAR-1 íntegro. No entanto, quando se trata de PAR-1 clivado, as plaquetas dos pacientes apresentaram menor expressão em relação aos controles.

No grupo de pacientes, assim como no grupo controle, a estimulação por trombina, ou SFLLRN foi capaz de induzir a formação de agregados entre plaquetas e leucócitos. Entretanto, observou-se que nos pacientes a resposta ocorreu predominantemente ao peptídeo SFLLRN, enquanto nos controles a estimulação com formação de agregados, ocorreu principalmente em resposta a trombina.

Os testes com a finalidade de identificar a expressão de selectina-P nas plaquetas, no estado basal, e após estimulação de PAR-1, não demonstraram diferenças significantes entre pacientes e controles. A estimulação do PAR-1 aumentou aproximadamente três vezes a expressão de selectina-P, em relação ao estado basal, porém isto ocorreu em ambos os grupos.

Não foram encontradas influências do número de plaquetas circulantes, e do número de hemácias circulantes (hematócrito) na expressão de PAR-1 (íntegro ou clivado), na magnitude de formação de agregados entre plaquetas e leucócitos, mediante estimulação, tanto de 
PAR-1 íntegro, quanto de PAR-1 clivado, e nem mesmo na expressão de selectina-P no estado basal, ou após estimulação.

Concluindo, as plaquetas dos pacientes com HAP, apresentaram características muito semelhantes às plaquetas de indivíduos normais, sendo assim, estão aptas a serem ativadas e formarem agregados, os quais podem obstruir pequenas artérias pulmonares, aumentando assim a resistência hemodinâmica, e conseqüentemente a pressão pulmonar. Desta forma, todo o cuidado no sentido de atenuar as respostas plaquetárias nestes pacientes é de extrema importância. 
ANEXOS 


\section{ANEXOS}

As tabelas apresentadas a seguir, contêm os valores individuais dos pacientes e controles obtidos em todos os testes realizados neste trabalho.

\subsection{Avaliação da expressão do PAR-1}

\subsubsection{Receptores íntegros (SPAN12)}

Os resultados relacionados com a reatividade plaquetária ao anticorpo SPAN12 estão dispostos na Tabela 5. Esta tabela é referente aos dados apresentados na Figura 6 e na Figura 7. 
Tabela 5 - Reatividade plaquetária ao anticorpo SPAN12

\begin{tabular}{|c|c|c|c|c|c|c|}
\hline & cientes & $\%+$ & IFM & Controles & $\%+$ & IFM \\
\hline 01 & A I & 21,39 & 19,58 & 01 & 60,07 & 13,28 \\
\hline 02 & JAN & 30,95 & 17,52 & 02 & 49,38 & 13,14 \\
\hline 03 & IDF & 34,22 & 41,21 & 03 & 32,13 & 11,39 \\
\hline 04 & G S M & 31,29 & 14,79 & 04 & 34,17 & 10,62 \\
\hline 05 & M G S & 29,82 & 13,05 & 05 & 44,89 & 14,49 \\
\hline 06 & HS Q & 31,25 & 15,76 & 06 & 41,24 & 15,7 \\
\hline 07 & $C E C$ & 35,98 & 16,62 & 07 & 51,1 & 15,57 \\
\hline 08 & M A O & 53,81 & 15,71 & 08 & 40,31 & 13,38 \\
\hline 09 & $C M V$ & 48,09 & 14,02 & 09 & 37,94 & 11,49 \\
\hline 10 & QNS & 56,1 & 15,31 & 10 & 24,65 & 9,88 \\
\hline 11 & MPS & 31,13 & 10,92 & 11 & 44,1 & 15,17 \\
\hline 12 & GD N & 32,96 & 13,04 & 12 & 49,93 & 13,54 \\
\hline 13 & G C C & 85,22 & 18,61 & 13 & 55,79 & 11,21 \\
\hline 14 & A S C & 42,7 & 14,07 & 14 & 31,36 & 11,37 \\
\hline 15 & $\mathrm{O} G \mathrm{~T}$ & 45,34 & 14,92 & 15 & 43,24 & 14,45 \\
\hline 16 & C AP & 40,53 & 12,79 & 16 & 43,58 & 12,03 \\
\hline 17 & EAR & 39,33 & 17,78 & 17 & 44,98 & 13,46 \\
\hline 18 & L J S & 41,8 & 17,17 & 18 & 34,13 & 11,24 \\
\hline 19 & VS S & 41,49 & 18,65 & 19 & 39,28 & 12,27 \\
\hline 20 & MRS & 43,39 & 12,9 & 20 & 41,86 & 13,18 \\
\hline 21 & $\mathrm{JAN}$ & 50,01 & 14,01 & 21 & 40,81 & 16,08 \\
\hline 22 & $H N Q$ & 21,56 & 10,63 & 22 & 64,46 & 23,66 \\
\hline 23 & EOS & 43,52 & 23,19 & 23 & 61,38 & 25,5 \\
\hline 24 & I C & 34,65 & 12,42 & 24 & 65,61 & 22,87 \\
\hline 25 & $O L J$ & 23,94 & 14,1 & 25 & 55,05 & 22,22 \\
\hline 26 & MDS & 51,96 & 20,65 & & & \\
\hline 27 & G B S & 47,71 & 22,46 & & & \\
\hline 28 & $A C C$ & 49,37 & 17,4 & & & \\
\hline 29 & RTF & 48,28 & 31,97 & & & \\
\hline 30 & $M \vee P$ & 54,15 & 19,76 & & & \\
\hline
\end{tabular}




\subsubsection{Receptores íntegros e clivados (ATAP2)}

Os resultados relacionados com a reatividade plaquetária ao anticorpo ATAP2 estão dispostos na Tabela 6. Esta tabela é referente aos dados apresentados na Figura 8 e na Figura 9.

Tabela 6 - Reatividade plaquetária ao anticorpo ATAP2

\begin{tabular}{|c|c|c|c|c|c|c|}
\hline & Pacientes & IFM & $\%+$ & Controles & IFM & $\%+$ \\
\hline 01 & A I & 57,44 & 60,41 & 01 & 26,82 & 93,78 \\
\hline 02 & $\mathrm{JAN}$ & 41,88 & 73,67 & 02 & 36,13 & 88,38 \\
\hline 03 & IDF & 82,2 & 67,71 & 03 & 27,59 & 74,66 \\
\hline 04 & GSM & 57,62 & 78,95 & 04 & 33,75 & 74,24 \\
\hline 05 & M G S & 25,58 & 74,88 & 05 & 33,41 & 82,23 \\
\hline 06 & $H S Q$ & 27,47 & 74,15 & 06 & 31,53 & 75,54 \\
\hline 07 & $C E C$ & 37,15 & 74,75 & 07 & 34,09 & 88,59 \\
\hline 08 & M A O & 36,34 & 78,18 & 08 & 28,19 & 85,27 \\
\hline 09 & $\mathrm{CMV}$ & 36,23 & 86,65 & 09 & 28,83 & 83,02 \\
\hline 10 & QNS & 38,36 & 85,63 & 10 & 15,76 & 57,37 \\
\hline 11 & MPS & 16,05 & 58,71 & 11 & 29,45 & 83,99 \\
\hline 12 & GD N & 28,26 & 76,65 & 12 & 33,5 & 87,78 \\
\hline 13 & $G C C$ & 31,62 & 82,01 & 13 & 23,43 & 85,92 \\
\hline 14 & A S C & 34,13 & 86,97 & 14 & 142,98 & 83,28 \\
\hline 15 & $\mathrm{OGT}$ & 30,13 & 77,73 & 15 & 37,23 & 82,18 \\
\hline 16 & CAP & 48,69 & 89,77 & 16 & 30,34 & 81,16 \\
\hline 17 & EAR & 89,78 & 82,7 & 17 & 24,15 & 81,94 \\
\hline 18 & L J S & 40,9 & 79,96 & 18 & 27,67 & 85,2 \\
\hline 19 & VS S & 178,2 & 78,78 & 19 & 25,47 & 80,82 \\
\hline 20 & M R S & 24,23 & 87,14 & 20 & 26,08 & 82,39 \\
\hline 21 & $\mathrm{JAN}$ & 26,64 & 72,74 & 21 & 51,01 & 80,8 \\
\hline 22 & $H N Q$ & 25,11 & 67,47 & 22 & 76,94 & 75,78 \\
\hline 23 & EOS & 44,1 & 42,53 & 23 & 48,09 & 80,58 \\
\hline 24 & IC & 23,54 & 79,05 & 24 & 56,18 & 86,56 \\
\hline 25 & O L J & 22,05 & 73,06 & 25 & 119,77 & 70,37 \\
\hline 26 & MDS & 82,42 & 72 & & & \\
\hline 27 & G B S & 56,21 & 80,28 & & & \\
\hline 28 & $A C C$ & 48,82 & 93,37 & & & \\
\hline 29 & R T F & 64,35 & 38,03 & & & \\
\hline 30 & $M \vee P$ & 129,56 & 76,84 & & & \\
\hline
\end{tabular}

IFM = intensidade de fluorescência média das plaquetas positivas (unidade arbitrária); $\%+=$ porcentagem de plaquetas positivas em relação aos 10.000 eventos adquiridos. 


\subsection{Avaliação da atividade do PAR-1}

\subsubsection{Formação de agregados plaqueta-leucócito (APL)}

Os resultados obtidos por citometria de fluxo e apresentados em porcentagem de formação de APL em relação ao total de eventos adquiridos (10.000) estão dispostos na Tabela 7, referente à Figura 10. Agregados plaqueta-leucócito ( $\mathrm{APL}$ ), foram caracterizados por eventos com dupla positividade, ou seja, eventos positivos tanto para CD42a-PerCP (plaquetas), quanto para CD45-FITC (leucócitos).

Tabela 7 - Porcentagem de formação de agregados plaqueta-leucócito em relação ao total de eventos adquiridos (10.000)

\begin{tabular}{lcccccccc}
\hline \multicolumn{2}{c}{ Pacientes } & $\begin{array}{c}\text { Basal } \\
\text { (\%) }\end{array}$ & $\begin{array}{c}\text { Trombina } \\
\text { (\%) }\end{array}$ & $\begin{array}{c}\text { SFLLRN } \\
\text { (\%) }\end{array}$ & $\begin{array}{c}\text { Controles } \\
\text { Basal } \\
\text { (\%) }\end{array}$ & $\begin{array}{c}\text { Trombina } \\
\text { (\%) }\end{array}$ & $\begin{array}{c}\text { SFLLRN } \\
\text { (\%) }\end{array}$ \\
\hline $\mathbf{0 1}$ & A I & 6,84 & 4,83 & 11,93 & $\mathbf{0 1}$ & 4,66 & 7,3 & 4,07 \\
$\mathbf{0 2}$ & J A N & 6,02 & 4,09 & 13,94 & $\mathbf{0 2}$ & 5,79 & 6,61 & 8,05 \\
$\mathbf{0 3}$ & I D F & 17,72 & 12,8 & 18,57 & $\mathbf{0 3}$ & 14,03 & 15,21 & 17,95 \\
$\mathbf{0 4}$ & G S M & 20,68 & 34,74 & 21,19 & $\mathbf{0 4}$ & 16,06 & 28,14 & 13,49 \\
$\mathbf{0 5}$ & M G S & 21,7 & 17,43 & 37,11 & $\mathbf{0 5}$ & 14,28 & 19,52 & 22,99 \\
$\mathbf{0 6}$ & H S Q & 11,8 & 18,71 & 12,36 & $\mathbf{0 6}$ & 14,8 & 36,63 & 17,31 \\
$\mathbf{0 7}$ & C E C & 10,64 & 21,64 & 23,39 & $\mathbf{0 7}$ & 25,28 & 31,15 & 20,53 \\
$\mathbf{0 8}$ & M A O & 9,98 & 4,23 & 15,3 & $\mathbf{0 8}$ & 15,69 & 20,34 & 19,31 \\
$\mathbf{0 9}$ & C M V & 14,85 & 20,33 & 19,82 & $\mathbf{0 9}$ & 35,54 & 39,51 & 33,07 \\
$\mathbf{1 0}$ & Q N S & 22,9 & 27,33 & 24,01 & $\mathbf{1 0}$ & 14,73 & 12,91 & 11,49 \\
$\mathbf{1 1}$ & M P S & 6,52 & 3,22 & 12,69 & $\mathbf{1 1}$ & 11,59 & 14,34 & 14,81 \\
$\mathbf{1 2}$ & G D N & 22,28 & 31,92 & 26,2 & $\mathbf{1 2}$ & 15,46 & 19,1 & 14,96 \\
$\mathbf{1 3}$ & G C C & 9,48 & 9,62 & 16,7 & $\mathbf{1 3}$ & 9,89 & 15,68 & 16,52 \\
$\mathbf{1 4}$ & A S C & 13,8 & 10,92 & 19,66 & $\mathbf{1 4}$ & 20,42 & 25,44 & 16,62 \\
$\mathbf{1 5}$ & O G T & 9,59 & 8,25 & 15,15 & $\mathbf{1 5}$ & 8,5 & 16,59 & 12,24 \\
$\mathbf{1 6}$ & C A P & 20,42 & 22,07 & 16,69 & $\mathbf{1 6}$ & 18,93 & 8,22 & 12,59 \\
$\mathbf{1 7}$ & E A R & 10,48 & 10,33 & 15,76 & $\mathbf{1 7}$ & 10,11 & 5,39 & 13,49 \\
$\mathbf{1 8}$ & L J S & 6,94 & 7,5 & 12,12 & $\mathbf{1 8}$ & 11,55 & 17,59 & 20,24 \\
$\mathbf{1 9}$ & V S S & 9,68 & 2,57 & 11,03 & $\mathbf{1 9}$ & 16,74 & 17,54 & 18,57 \\
$\mathbf{2 0}$ & M R S & 9,17 & 10,9 & 14,18 & $\mathbf{2 0}$ & 12,43 & 13,75 & 15,62 \\
$\mathbf{2 1}$ & J A N & 10,2 & 12,87 & 14,83 & $\mathbf{2 1}$ & 23,84 & 39,13 & 22,45 \\
$\mathbf{2 2}$ & H N Q & 11,18 & 16,04 & 18,69 & $\mathbf{2 2}$ & 19,31 & 14,22 & 17,51 \\
$\mathbf{2 3}$ & E O S & 2,7 & 0,17 & 7,71 & $\mathbf{2 3}$ & 18,68 & 14,12 & 22,72 \\
$\mathbf{2 4}$ & I C & 14,5 & 6,12 & 15,23 & $\mathbf{2 4}$ & 22,16 & 35,96 & 21,54 \\
$\mathbf{2 5}$ & O L J & 4,12 & 3,33 & 4,25 & $\mathbf{2 5}$ & 16,15 & 40,87 & 23,29 \\
$\mathbf{2 6}$ & M D S & 19,78 & 30,95 & 22,14 & & & & \\
$\mathbf{2 7}$ & G B S & 14,1 & 19,67 & 17,51 & & & & \\
$\mathbf{2 8}$ & A C C & 15,53 & 18,39 & 22,28 & & & & \\
$\mathbf{2 9}$ & R T F & 24,8 & 32,87 & 26,39 & & & & \\
$\mathbf{3 0}$ & M V P & 25,68 & 24,68 & 27,03 & & & & \\
\hline
\end{tabular}




\subsubsection{Formação de agregados plaqueta-monócito (APM)}

Os resultados obtidos por citometria de fluxo e apresentados em porcentagem de formação de APM em relação ao total de eventos adquiridos (10.000) estão dispostos na Tabela 8, referente à Figura 11. Agregados plaqueta-monócito (APM), foram caracterizados por eventos com dupla positividade, ou seja, eventos positivos tanto para CD42a-PerCP (plaquetas), quanto para CD14-PE (monócitos).

Tabela 8 - Porcentagem de formação de agregados plaqueta-monócito em relação ao total de eventos adquiridos (10.000)

\begin{tabular}{lcccccccc}
\hline & Pacientes & $\begin{array}{c}\text { Basal } \\
\text { (\%) }\end{array}$ & $\begin{array}{c}\text { Trombina } \\
\text { (\%) }\end{array}$ & $\begin{array}{c}\text { SFLLRN } \\
\mathbf{( \% )}\end{array}$ & $\begin{array}{c}\text { Controles } \\
\text { Basal } \\
\text { (\%) }\end{array}$ & $\begin{array}{c}\text { Trombina } \\
\text { (\%) }\end{array}$ & $\begin{array}{c}\text { SFLLRN } \\
\text { (\%) }\end{array}$ \\
\hline $\mathbf{0 1}$ & A I & 2,14 & 3,58 & 4,92 & $\mathbf{0 1}$ & 1,85 & 8,5 & 1,95 \\
$\mathbf{0 2}$ & J A N & 5,72 & 6,28 & 5,65 & $\mathbf{0 2}$ & 2,69 & 9,8 & 3 \\
$\mathbf{0 3}$ & I D F & 6,23 & 13,3 & 5,16 & $\mathbf{0 3}$ & 4,98 & 16,29 & 4,07 \\
$\mathbf{0 4}$ & G S M & 9,38 & 44,36 & 6,4 & $\mathbf{0 4}$ & 9,12 & 42,83 & 5,92 \\
$\mathbf{0 5}$ & M G S & 3,2 & 13,09 & 3,6 & $\mathbf{0 5}$ & 2,55 & 23,94 & 4,3 \\
$\mathbf{0 6}$ & H S Q & 4,33 & 29,12 & 4,72 & $\mathbf{0 6}$ & 3,6 & 52,81 & 7,05 \\
$\mathbf{0 7}$ & C E C & 3,64 & 31,99 & 4,47 & $\mathbf{0 7}$ & 3,7 & 40,38 & 2,68 \\
$\mathbf{0 8}$ & M A O & 6,61 & 4,71 & 8,26 & $\mathbf{0 8}$ & 4,33 & 25,02 & 4,05 \\
$\mathbf{0 9}$ & C M V & 4,2 & 20,66 & 3,85 & $\mathbf{0 9}$ & 5,05 & 47,41 & 2,81 \\
$\mathbf{1 0}$ & Q N S & 3,19 & 29,06 & 3,66 & $\mathbf{1 0}$ & 3,11 & 15,26 & 3,92 \\
$\mathbf{1 1}$ & M P S & 3,88 & 3,75 & 5,79 & $\mathbf{1 1}$ & 4,01 & 11,62 & 2,84 \\
$\mathbf{1 2}$ & G D N & 4,26 & 30,16 & 3,96 & $\mathbf{1 2}$ & 2,73 & 22,39 & 2,33 \\
$\mathbf{1 3}$ & G C C & 2,55 & 6,63 & 4,32 & $\mathbf{1 3}$ & 4,34 & 19,16 & 11,35 \\
$\mathbf{1 4}$ & A S C & 3,58 & 11,97 & 3,72 & $\mathbf{1 4}$ & 2,52 & 31,2 & 3,43 \\
$\mathbf{1 5}$ & O G T & 5,55 & 9,58 & 7,77 & $\mathbf{1 5}$ & 2,95 & 20,47 & 2,02 \\
$\mathbf{1 6}$ & C A P & 2,52 & 25,07 & 4,18 & $\mathbf{1 6}$ & 4,8 & 8,89 & 3,42 \\
$\mathbf{1 7}$ & E A R & 3,47 & 9,85 & 6,09 & $\mathbf{1 7}$ & 3,39 & 5,64 & 1,26 \\
$\mathbf{1 8}$ & L J S & 2,55 & 8,4 & 3,5 & $\mathbf{1 8}$ & 4,22 & 19,6 & 2,82 \\
$\mathbf{1 9}$ & V S S & 3,15 & 2,39 & 3,12 & $\mathbf{1 9}$ & 3,74 & 18,83 & 3,44 \\
$\mathbf{2 0}$ & M R S & 3,81 & 12,22 & 3,28 & $\mathbf{2 0}$ & 3,65 & 14 & 2,7 \\
$\mathbf{2 1}$ & J A N & 4,16 & 13,42 & 5,44 & $\mathbf{2 1}$ & 11,36 & 42,01 & 8,23 \\
$\mathbf{2 2}$ & H N Q & 4,98 & 18,11 & 4,17 & $\mathbf{2 2}$ & 4,61 & 12,58 & 6,49 \\
$\mathbf{2 3}$ & E O S & 1,11 & 0,11 & 2,08 & $\mathbf{2 3}$ & 6,23 & 12,13 & 10,79 \\
$\mathbf{2 4}$ & I C & 4,86 & 6,21 & 3,93 & $\mathbf{2 4}$ & 6,89 & 38,25 & 4,74 \\
$\mathbf{2 5}$ & O L J & 2,3 & 4,42 & 2,36 & $\mathbf{2 5}$ & 5,62 & 46,36 & 9,32 \\
$\mathbf{2 6}$ & M D S & 11,31 & 35,58 & 9,66 & & & & \\
$\mathbf{2 7}$ & G B S & 4,05 & 22,75 & 6,49 & & & & \\
$\mathbf{2 8}$ & A C C & 6,62 & 20,18 & 8,99 & & & & \\
$\mathbf{2 9}$ & R T F & 10,06 & 30,85 & 9,28 & & & & \\
$\mathbf{3 0}$ & M V P & 13,68 & 23,44 & 9,3 & & & & \\
\hline
\end{tabular}




\subsection{Avaliação da expressão da selectina-P das plaquetas no estado} basal e após estimulação

Os resultados da reatividade à selectina- $P$, expressos em IFM, na condição basal e após estimulação das plaquetas por TRAP, obtidos por citometria de fluxo estão dispostos na Tabela 9, referente à Figura 12.

Tabela 9 - Reatividade à selectina-P (CD62P) das plaquetas após estimulação por TRAP

\begin{tabular}{|c|c|c|c|c|c|c|}
\hline & Pacientes & $\begin{array}{l}\text { Basal } \\
\text { (IFM) }\end{array}$ & $\begin{array}{l}\text { TRAP } \\
\text { (IFM) }\end{array}$ & Controles & $\begin{array}{l}\text { Basal } \\
\text { (IFM) }\end{array}$ & $\begin{array}{l}\text { TRAP } \\
\text { (IFM) }\end{array}$ \\
\hline 01 & Al & 42,1 & 131,77 & 01 & 48,81 & 321,01 \\
\hline 02 & JAN & 26,71 & 67,07 & 02 & 23,82 & 85,4 \\
\hline 03 & I D F & 38,47 & 186,11 & 03 & 27,15 & 123,9 \\
\hline 04 & G S M & 26,76 & 79,64 & 04 & 29,26 & 112,12 \\
\hline 05 & M G S & 41,25 & 62,75 & 05 & 36,82 & 62,69 \\
\hline 06 & $H S Q$ & 29,5 & 82,98 & 06 & 23,91 & 129,91 \\
\hline 07 & C E C & 35,68 & 73,35 & 07 & 31,72 & 115,37 \\
\hline 08 & M A O & 38,96 & 140,42 & 08 & 40,39 & 139,98 \\
\hline 09 & C M V & 29,04 & 101,61 & 09 & 23,42 & 96,41 \\
\hline 10 & Q NS & 29,07 & 83,89 & 10 & 28,41 & 72,4 \\
\hline 11 & M P S & 28,26 & 53,29 & 11 & 36,4 & 91,89 \\
\hline 12 & GD N & 25,75 & 77,64 & 12 & 46,04 & 107,85 \\
\hline 13 & G C C & 33,79 & 91,27 & 13 & 40,13 & 117,26 \\
\hline 14 & A S C & 41,17 & 120,73 & 14 & 32,29 & 135,29 \\
\hline 15 & $\mathrm{OG} \mathrm{T}$ & 21,73 & 80,18 & 15 & 38,12 & 81,52 \\
\hline 16 & CAP & 42,64 & 134,13 & 16 & 30,13 & 115,3 \\
\hline 17 & E A R & 32 & 129,12 & 17 & 35,48 & 130,53 \\
\hline 18 & L JS & 36,96 & 115,58 & 18 & 30,92 & 109,38 \\
\hline 19 & VSS & 36,06 & 129,13 & 19 & 34,75 & 85,95 \\
\hline 20 & MRS & 31,33 & 88,52 & 20 & 25,62 & 40,86 \\
\hline 21 & J A N & 36,45 & 121,82 & 21 & 70,31 & 748,5 \\
\hline 22 & $\mathrm{HNQ}$ & 29,37 & 99,69 & 22 & 49,31 & 139,36 \\
\hline 23 & EOS & 26,82 & 67,03 & 23 & 30,08 & 69,23 \\
\hline 24 & I C & 30,02 & 71,46 & 24 & 74,86 & 118,34 \\
\hline 25 & O L J & 32,74 & 51,02 & 25 & 56,22 & 110,11 \\
\hline 26 & MDS & 92,89 & 104,65 & & & \\
\hline 27 & G B S & 65,97 & 108,53 & & & \\
\hline 28 & $A C C$ & 62,19 & 89,06 & & & \\
\hline 29 & R T F & 53,23 & 160,81 & & & \\
\hline 30 & $M \vee P$ & 49,15 & 110,55 & & & \\
\hline
\end{tabular}

IFM = Intensidade de fluorescência média 
REFERÊNCIAS BIBLIOGRÁFICAS 


\section{REFERÊNCIAS BIBLIOGRÁFICAS}

1. Andrade-Gordon $\mathrm{P}$, Derian $\mathrm{CK}$, Maryanoff $\mathrm{BE}$, Zhang $\mathrm{H}-\mathrm{C}$, Addo MF, Cheung WM, Damiano BP, D'Andrea MR, Darrow AL, DeGaravilla L. Administration of a potent antagonist of PAR-1 attenuates vascular restenosis following balloon angioplasty in rats. J Pharmacol Exp Ther. 2001;298:34-42.

2. Andre P. P-Selectin in haemostasis. Br J Haematol. 2004;126:298-306.

3. Andrews RK, Gardiner EE, Shen Y, Berndt MC. Platelets interactions in thrombosis. IUBMB Life. 2004;56:13-8.

4. Bahou WF. Attacked from within, blood thins. Nat Med. 2002;8:1082-93.

5. Barrett NE, Holbrook L, Jones S, Kaiser WJ, Moraes LA, Rana R, Sage T, Stanley RG, Tucker KL, Wright B, Gibbins JM. Future innovations in antiplatelet therapies. Br J Pharmacol. 2008;154:918-39.

6. Barst RJ, McGoon M, Torbicki A, Sitbon O, Krowka MJ, Olschewski H, Gaine $\mathrm{S}$. Diagnosis and differential assessment of pulmonary arterial hypertension. J Am Coll Cardiol. 2004;43:40S-47S.

7. Brass LF, Pizzaro S, Ahuja M, Belmonte E, Blanchard N, Stadel JM, Hoxie, JA. Changes in the structure and function of the human thrombin receptor during receptor activation, internalization and recycling. $\mathrm{J}$ Biol Chem. 1994;269:2943-52.

8. Brass LF, Vassallo RR, Belmonte E, Ahuja M, Chichowski k, Hoxie JÁ. Structure and function of the human platelet thrombin receptor. Studies using monoclonal antibodies directed against a defined domain within the receptor $\mathrm{N}$ terminus. J Biol Chem. 1992;15:13795-8.

9. Brass LF. The molecular basis of platelet activation. In: Hoffman R, Benz E, Shattil S, Furie B, Cohen $H$, Silberstein LE, McGlave $P$, editores. Hematology: basic principles and practice. 4a ed. Philadelphia: Churchill Livingstone; 2005. p.1899-914.

10. Caramurú LH, Soares RP, Maeda NY, Lopes AA. Hypoxia and altered platelet behavior influence von Willebrand factor multimeric composition in secondary pulmonary hypertension. Clin Appl Thromb Hemost. 2003;9:2518.

11. Coppinger, JA, O'Connor, R, Wynne, K, Flanagan M, Sullivan M, Maguire PB, Fitzgerald DJ, Cagney G. Moderation of the platelet releasate response by aspirin. Blood. 2007;109:4786-92.

12. Coughlin SR. Thrombin signaling and protease activated receptors. Nature. 2000;407:258-64. 
13. Crago AM, Wu HF, Hoffman M, Church FC. Monocyte chemoattractant activity of Ser195-->Ala active site mutant recombinant alpha-thrombin. Exp Cell Res. 1995;219:650-6.

14. Damås JK, Otterdal K, Yndestad A, Aass H, Solum NO, Frøland SS, Simonsen S, Aukrust P, Andreassen AK. Soluble CD40 ligand in pulmonary arterial hypertension: possible pathogenic role of the interaction between platelets and endothelial cells. Circulation. 2004;110:999-1005.

15. Day JR, Haskard DO, Taylor KM, Landis RC. Effect of aprotinin and recombinant variants on platelet protease-activated receptor 1 activation. Ann Thorac Surg. 2006;81:619-24.

16. Day JRS, Punjabi PP, Randi AM, Haskard DO, Landis RC, Taylor MD. Clinical inhibition of the seven-transmembrane thrombin receptor (PAR1) by intravenous aprotinin during cardiothoracic surgery. Circulation. 2004;110:2597-600.

17. Dery O, Corvera CU, Steinhoff M, Bunnett NW. Proteinase-activated receptors: novel mechanisms of sinaling by serine proteases. Am J Physiol. 1998;274:1429-52.

18. Dore M. Platelet-leukocyte interactions. Am Heart J. 1998;135:S146-S151.

19. Ebbe S. Biology of megakaryocytes. Prog Hemost Thromb. 1976;3:211-29.

20. Eddahibi S, Humbert M, Fadel E, Raffestin B, Darmon M, Capron F, Simonneau G, Dartevelle P, Hamon M, Adnot S. Serotonin transport overexpression is responsible for pulmonary artery smooth muscle hyperplasia in primary pulmonary hypertension. $\mathrm{J}$ Clin Invest. 2001;108:1141-50.

21. Elalamy I, Chakroun T, Gerotziafas GT, Petropoulou A, Robert F, Karroum A, Elgrably $F$, Samama MM, Hatmi M. Circulating platelet-leukocyte aggregates: a marker of microvascular injury in diabetic patients. Thromb Res. 2008;121:843-8.

22. Ferraris VA, Ferraris SP, Singh A, Fuhr W, Koppel D, McKenna D, Rodriguez $E$, Reich $H$. The platelet thrombin receptor and postoperative bleeding. Ann Thorac Surg. 1998;62:352-8.

23. Frenette PS, Johnson RC, Hynes RO, Wagner DD. Platelets roll on stimulated endothelium "in vivo": an interaction mediated by endothelial Pselectin. Proc Natl Acad Sci U S A. 1995;92:7450-4.

24. Furman MI, Benoit SE, Barnard MR, Valeri CR, Borbone ML, Becker RC, Hechtman HB, Michelson AD. Increased platelet reactivity and circulating monocyte-platelet aggregates in patients with stable coronary artety disease. J Am Coll Cardiol. 1998;31:352-8. 
25. Gawaz M, Brand K, Dickfeld T, Pogatsa-Murray G, Page S, Bogner C, Koch W, Schömig A, Neumann F. Platelets induce alterations of chemotactic and adhesive properties of endothelial cells mediated through an interleukin-1dependent mechanism. Implications for atherogenesis. Atherosclerosis. 2000;148:75-85.

26. Gawaz M. Role of platelets in coronary thrombosis and reperfusion of ischemic myocardium. Cardiovasc Res. 2004;61:498-511.

27. Giaid A, Saleh D. Reduced expression of endothelial nitric oxide synthase in the lungs of patients with pulmonary hypertension. $N$ Engl $\mathrm{J}$ Med. 1995;333:214-21.

28. Henn V, Slupsky JR, Grafe M, Anagnostopoulos I, Forster R, MullerBerghaus G, Kroczek RA. CD40 ligand on activated platelets triggers an inflammatory reaction of endothelial cells. Nature. 1998;391:591-4.

29. Hervé P, Drouet L, Dosquet C, Launay JM, Rain B, Simonneau G, Caen J, Duroux $P$. Primary pulmonary hypertension in a patient with a familial platelet storage pool disease: role of serotonin. Am J Med. 1990;89:117-20.

30. Hervé P, Humbert M, Sitbon O, Parent F, Nunes H, Legal C, Garcia G, Simonneau G. Pathobiology of pulmonary hypertension. The role of platelets and thrombosis. Clin Chest Med. 2001;22:451-8.

31. Hirano $\mathrm{K}$, Kanaide $\mathrm{H}$. Role of protease-activated receptors in vascular system. J Atheroscler Thromb. 2003;10:211-25.

32. Hollenberg MD, Compton SJ. Proteinase-activated receptors. Pharmacol Rev. 2002;54:203-17.

33. Hung DT, Wong YH, Vu TK, Coughlin SR. The cloned platelet thrombin receptor couples to at least two distinct effectors to stimulate phosphoinositide hydrolysis and inhibit. J Biol Chem. 1992;267:20831-4.

34. Ishihara H, Connolly AJ, Zeng D, Kahn ML, Zheng YW, Timmons C,Tram T, Coughlin SR. Protease-activated receptor 3 is a second thrombin receptor in humans. Nature. 1997;386:502-6.

35. Johnston GI, Cook RG, McEver RP. Cloning of GMP-140, a granule membrane protein of platelets and endothelium: Sequence similarity to proteins involved in cell adhesion and inflammation. Cell. 1989;56:1033-44.

36. Jungi TW, Spycher MO, Nydegger UE, Barandun S. Platelet-leukocyte interaction: selective binding of thrombin-stimulated platelets to human monocytes, polymorphonuclear leukocytes, and related cell lines. Blood. 1986;67:629-36.

37. Kahn ML, Hammes SR, Botka C, Coughlin SR. Gene and locus structure and chromosomal localization of the protease-activated receptor gene family. J Biol Chem. 1998;273:23290-6. 
38. Kéreveur A, Callebert J, Humbert M, Hervé P, Simonneau G, Launay JM, Drouet L. High plasma serotonin levels in primary pulmonary hypertension. Effect of long-term epoprostenol (prostacyclin) therapy. Arterioscler Thromb Vasc Biol. 2000;20:2233-9.

39. Kleiman NS, Freedman JE, Tracy PB, Furie BC, Bray PF, Rao SV, Phillips DR, Storey RF, Rusconi CP, French PA, Steinhubl SR, Becker RC. Platelets: developmental biology, physiology, and translatable platforms for preclinical investigation and drug development. Platelets. 2008;19:239-51.

40. Konishi H, Katoh Y, Takaya N, Kashiwakura Y, Itoh S, Ra C, Daida H. Platelets activated by collagen through immunoreceptor tyrosine-based activation motif play pivotal role in initiation and generation of neointimal hyperplasia after vascular injury. Circulation. 2002;105:912-6.

41. Lippuner N, Morell B, Schaffner A, Schaer DJ. Proteinase-activated receptors induce nonoxidative, antimicrobial peptides and increased antimicrobial activity in human mononuclear phagocytes. J Leukoc Biol. 2007;81:465-73.

42. Lopes AA, Maeda NY, Almeida A, Jaeger R, Ebaid M, Chamone DF. Circulating platelet aggregates indicative of "in vivo" platelet activation in pulmonary hypertension. Angiology. 1993;44:701-6.

43. Maeda NY, Bydlowski SP, Lopes AAB. Increased tyrosine phosphorylation of platelet proteins including pp125FAK suggests endogenous activation and aggregation in pulmonary hypertension. Aceito para publicação Clin Appl Thromb Hemost 2004a.

44. MacFarlane SR, Seatter MJ, Kanke T, Hunter GD, Plevin R. Proteinaseactivated receptors. Pharmacol Rev. 2001;53:245-82.

45. McEver RP: Adhesive interactions of leukocytes, platelets, and the vessel wall during hemostasis and inflammation. Thromb Haemost. 2001;86:74656.

46. Maeda NY, Bydlowski SP, Lopes AAB. Platelet GPIlb/Illa non-receptor tyrosine kinases pp60c-src and pp125FAK in patients with advanced pulmonary hypertension. Eur Heart J. 2002;23:113-

47. Maeda NY, Bydlowski SP, Lopes AAB. Increased tyrosine phosphorylation of platelet proteins including pp125FAK suggests endogenous activation and aggregation in pulmonary hypertension. Clin Appl Thromb Hemost. 2005;11:411-5.

48. Maeda NY, Bydlowski S, Lopes AA. Enhanced tyrosine phosphorylation of platelet substrates including pp60c-src and pp125FAK is indicative of endogenous platelet activation in pulmonary vaso-occlusive disease. Cardiovasc Pathol 2004b;13:S122. 
49. Markewitz BA, Farrukh IS, Chen Y, Li Y, Michael JR. Regulation of endothelin-1 synthesis in human pulmonary arterial smooth muscle cells: effects of transforming growth factor- $\beta$ and hypoxia. Cardiovasc Res. 2001;29:200-6.

50. Maugeri N, Di Fabio G, Barbanti M, Gaetano G, Donati MB, Cerletti C. Parnaparin, a low-molecular-weight heparin, prevents P-selectin-dependent formation of platelet-leukocyte aggregates in human whole blood. Thromb Haemost. 2007;97:965-73.

51. Michelson AD, Barnard MR, Hechtman HB, MacGregor $H$, Connolly RJ, Loscalzo J, Valeri CR. "in vivo" tracking of platelets: circulating degranulated platelets rapidly lose surface P-selectin but continue to circulate and function. Proc Natl Acad Sci USA. 1996;93:11877-82.

52. Michelson AD, Barnard MR, Krueger LA, Valeri CR, Furman MI. Circulating monocyte-platelet aggregates are a more sensitive marker of "in vivo" platelet activation than platelet surface P-selectin: studies in baboons, human coronary intervention, and human acute myocardial infarction. Circulation. 2001;104:1533-7.

53. Molino M, Blanchard N, Belmonte E, Tarver AP, Abrams C, Hoxie JA, Cerletti C, Brass LF. Proteolysis of the human platelet and endothelial cell thrombin receptor by neutrophil-derived cathepsin G. J Biol Chem. 1995;270:11168-75.

54. Nystedt S, Emilsson K, Wahlestedt C, Sundelin J. Molecular cloning of a potential proteinase activated receptor. Proc Natl Acad Sci USA. 1994;91:9208-12.

55. Offermanns S. Activation of platelet function through $G$ protein-coupled receptors. Circ Res. 2006;99;1293-304.

56. Palabrica T, Lobb R, Furie BC, Aronovitz M, Benjamin C, Hsu Y, Sajer SA, Furie $\mathrm{B}$. Leukocyte accumulation promoting fibrin deposition is mediated "in vivo" by P-selectin on adherent platelets. Nature. 1992;359:848-51.

57. Patel-Hett, S, Richardson, JL, Schulze, H, Drabek K, Isaac NA, Hoffmeister K, Shivdasani RA, Bulinski JC, Galjart N, Hartwig JH, Italiano JE Jr. Visualization of microtubule growth in living platelets reveals a dynamic marginal band with multiple microtubules. Blood. 2008;111:4605-16.

58. Perros F, Montani D, Dorfmüller P, Durand-Gasselin I, Tcherakian C, Le Pavec J, Mazmanian M, Fadel E, Mussot S, Mercier O, Hervé P, Emilie D, Eddahibi S, Simonneau G, Souza R, Humbert M. Platelet-derived growth factor expression and function in idiopathic pulmonary arterial hypertension. Am J Respir Crit Care Med. 2008;178:81-8.

59. Plow EF, Abrams CS. The molecular basis for platelet function. In: Hoffman R, Benz E, Shattil S, Furie B, Cohen H, Silberstein LE, McGlave P, editores. Hematology: basic principles and practice. 4a ed. Philadelphia: Churchill Livingstone; 2005. p.1881-97. 
60. Poullis M, Manning R, Laffan M, Haskard DO, Taylor KM, Landis RC. The antithrombotic effect of aprotinin: actions mediated via protease-activated receptor-1. J Thorac Cardiovasc Surg. 2000;120:370-8.

61. Rabinovitch M. Pathobiology of pulmonary hypertension. Extracellular matrix. Clin Chest Med. 2001;22:433-49.

62. Ramström S, Öberg KV, Åkerström F, Enström C, Lindahl TL. Platelet PAR1 receptor density: correlation to platelet activation response and changes in exposure after platelet activation. Thromb Res. 2008;121:681-8

63. Reiter R, Derhaschnig U, Spiel A, Keen P, Cardona F, Mayr F, Jilma B. Regulation of protease-activated receptor 1 (PAR1) on platelets and responsiveness to thrombin receptor activating peptide (TRAP) during systemic inflammation in humans. Thromb Haemost. 2003;90:898-903.

64. Rendu F, Brohard-Bohn B. The platelet release reaction: granule's constituents, secretion and functions. Platelets. 2001;12:261-73.

65. Rinder HM, Bonan JL, Rinder CS, Ault KA, Smith BR. Activated and unactivated platelet adhesion to monocytes and neutrophils. Blood. 1991;78:1760-9.

66. Ruggeri ZM. Platelets in atherothrombosis. Nat Med. 2002;8:1227-34.

67. Sako D, Chang XJ, Barone KM, Vachino G, White HM, Shaw G, Veldman $\mathrm{GM}$, Bean KM, Ahern TJ, Furie B. Expression cloning of a functional glycoprotein ligand for P-selectin. Cell. 1993;75:1179-86.

68. Samara WM, Gurbel PA. The role os platelet receptors and adhesion molecules in coronary artery disease. Coron Artery Dis. 2003;14:65-79.

69. Sarma J, Laan CA, Alam S, Jha A, Fox KA, Dransfield I. Increased platelet binding to circulating monocytes in acute coronary syndromes. Circulation. 2002;105:2166-71.

70. Shapiro HM. Practical flow cytometry. 4a ed. New Jersey: John Wiley and Sons, Inc; 2003. Cap.1, p.1-60: Overture.

71. Shi Y, Massague J. Mechanisms of TGF-beta signaling from cell membrane to nucleus. Cell. 2003;113:685-700.

72. Simon DI, Chen Z, Xu H, Li CQ, Dong J, Mclntire LV, Ballantyne CM, Zhang $\mathrm{L}$, Furman MI, Berndt MC, López JA. Platelet glycoprotein Ibalpha is a counterreceptor for the leukocyte integrin Mac-1 (CD11b/CD18). J Exp Med. 2000;192:193-204.

73. Simonneau G, Galiè N, Rubin LJ, Langleben D, Seeger W, Domenighetti G, Gibbs S, Lebrec D, Speich R, Beghetti M, Rich S, Fishman A. Clinical classification of pulmonary hypertension. J Am Coll Cardiol. 2004;43:S5-S12. 
74. Stenberg PE, McEver RP, Shuman MA, Jacques YV, Bainton DF. A platelet alpha-granule membrane protein (GMP-140) is expressed on the plasma membrane after activation. J Cell Biol. 1985;101:880-6.

75. Vassallo RR Jr, Kieber-Emmons T, Cichowski K, Brass LF. Structurefunction relationships in the activation of platelet thrombin receptors by receptor-derived peptides. J Biol Chem. 1992;267:6081-85.

76. Vretenbrant K, Ramström S, Bjerke M, Lindahl TL. Platelet activation via PAR-4 is involved in the initiation of thrombin generation and clot elasticity development. Thromb Haemost. 2007;93:417-24.

77. Vu TK, Hung DT, Wheaton VI, Coughlin SR. Molecular cloning of a functional thrombin receptor reveals a novel proteolytic mechanism of receptor activation. Cell. 1991;64:1057-68.

78. Wagner DD, Burger PC. Platelets in inflammation and thrombosis. Arterioscler Thromb Vasc Biol. 2003;23:2131-7.

79. Woolkalis MJ, Demelfi TM, Blanchard N, Hoxie JA, Brass LF. Regulation of thrombin receptors on human umbilical vein endothelial cells. J Biol Chem. 1995;270:9868-75. 
Da perfeição da vida

Por que prender a vida em conceitos e normas?

O Belo e o Feio... O Bom, e o Mau, e Dor e Prazer...

Tudo, afinal, são normas

E não degraus do ser! 